$\infty$
$\infty$
0
$z$
0
0
0
0
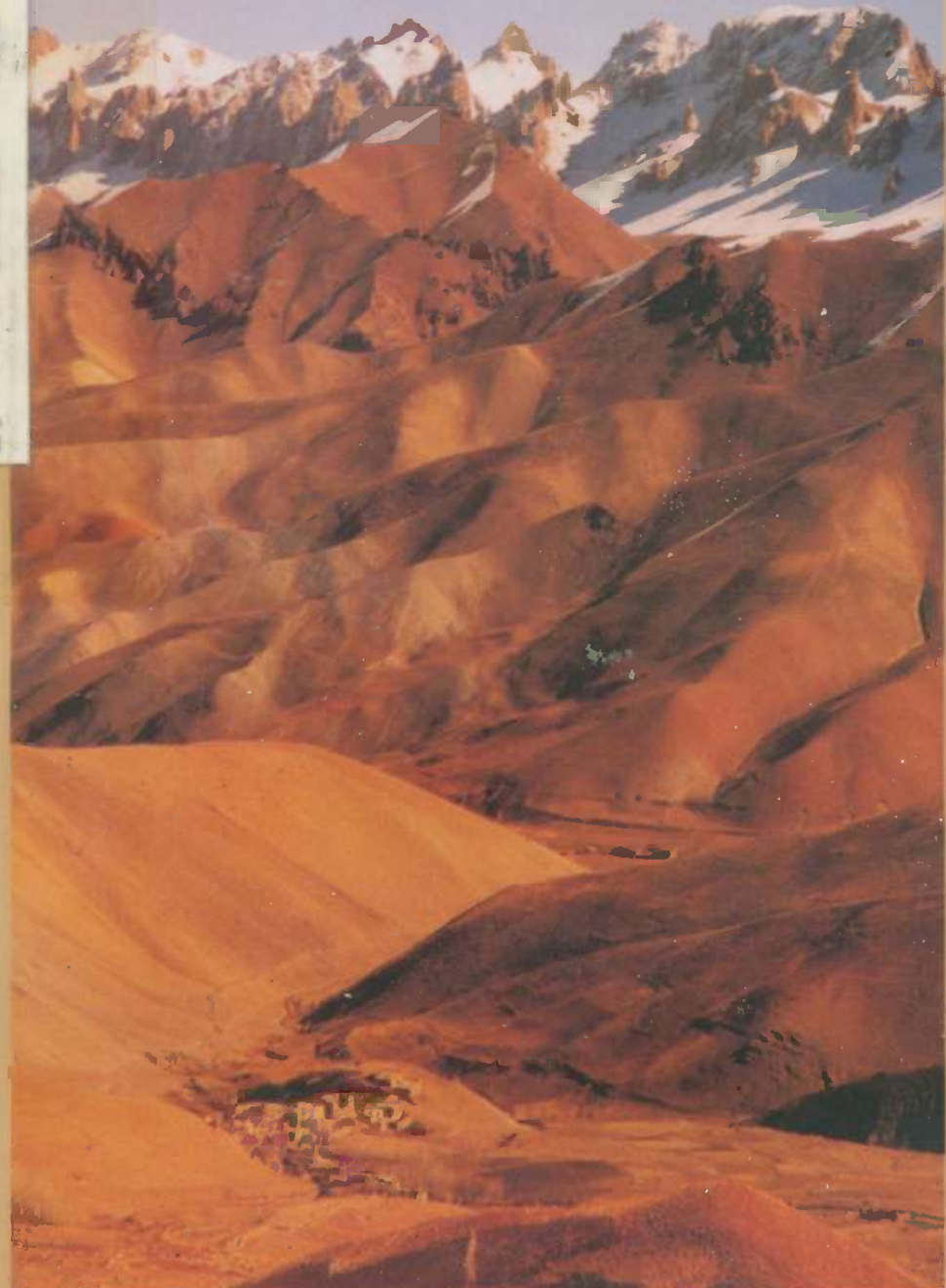

Women's Health in the
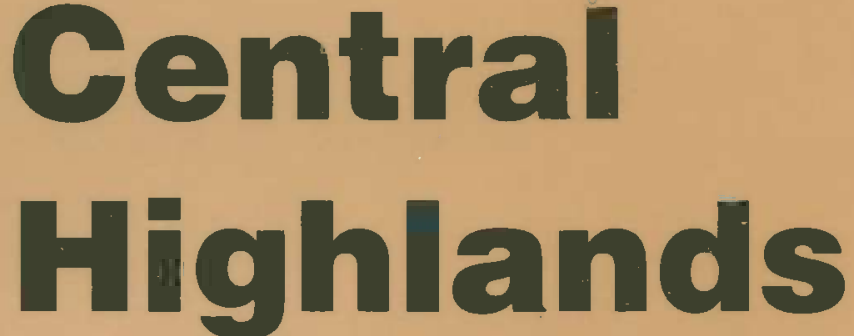

Report of the PRA in Yakawlang and Punjao Districts of Bamyan, Afghanistan, June 1998
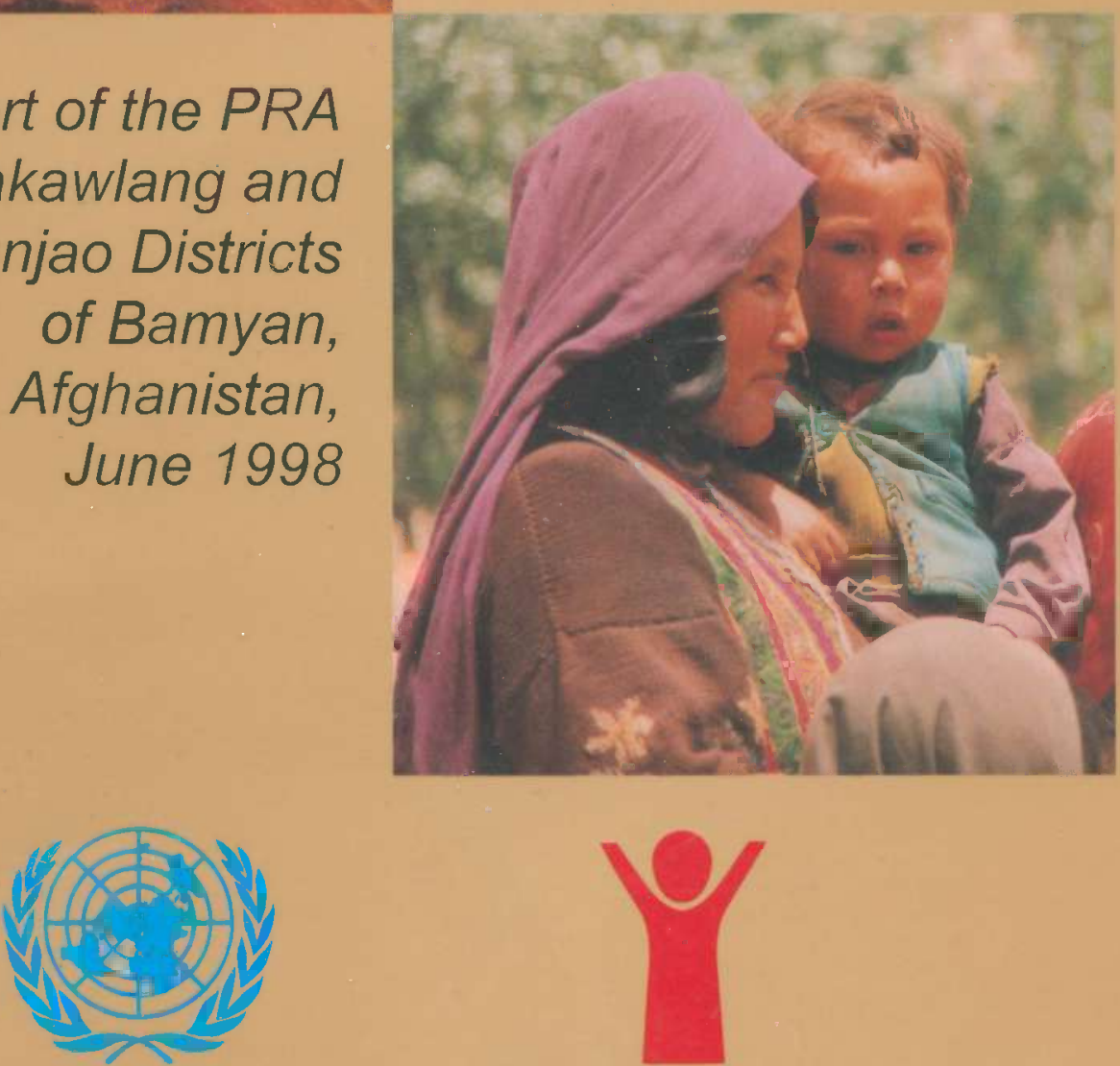

UNOPS - UNDP Save the Children 


\section{Women's Health in the Central Highlands}

Report of the PRA in Yakawlang \& Panjao Districts of Bamyan, Afghanistan June 1998

\section{By Sharon Lash}

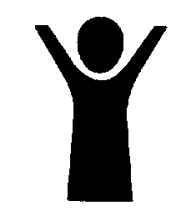

Save the Children
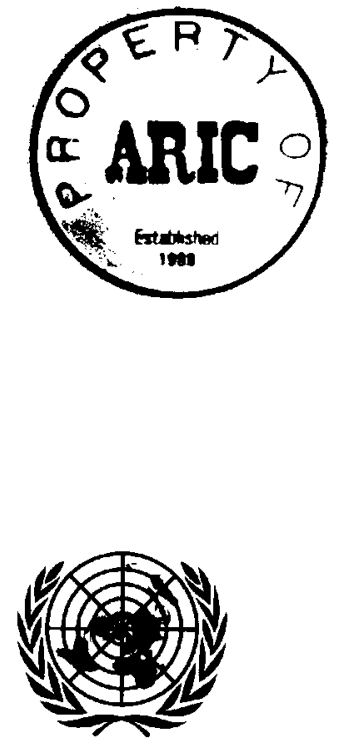

UNOPS 


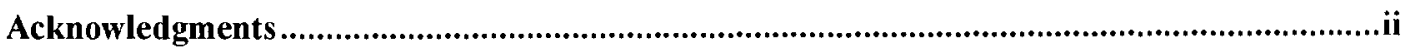

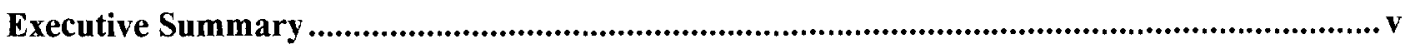

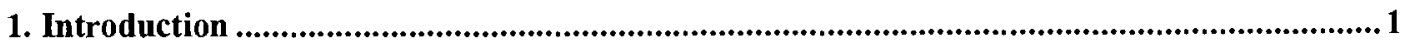

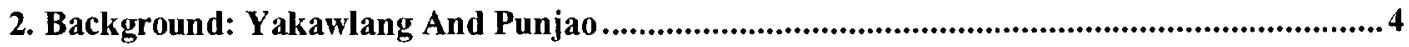

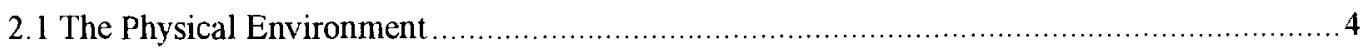

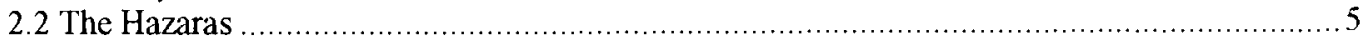

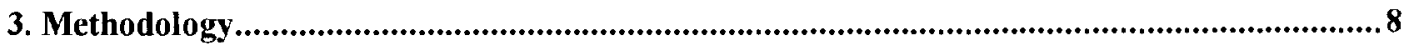

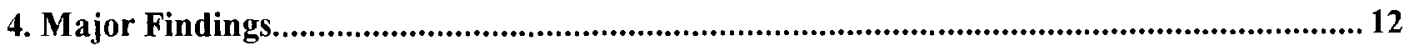

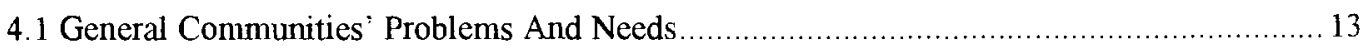

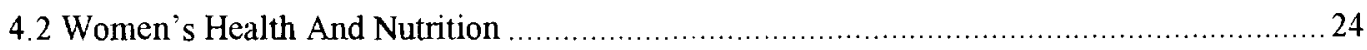

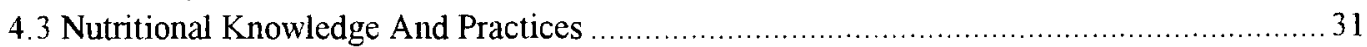

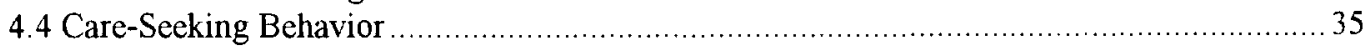

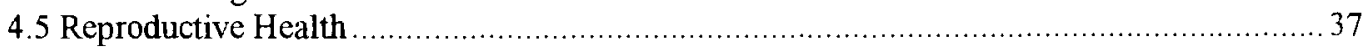

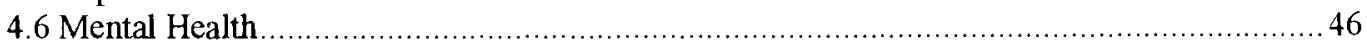

4.7 Gender Issues And Attitudes Toward Women And Girls .......................................... 51

5. Conclusions And Recommendations..................................................................................60

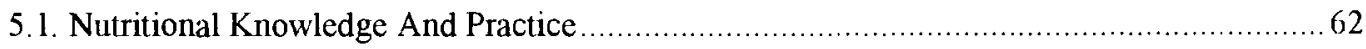

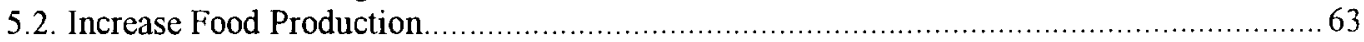

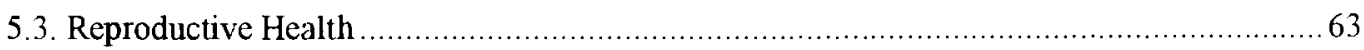

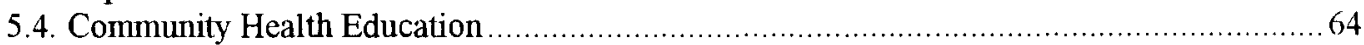

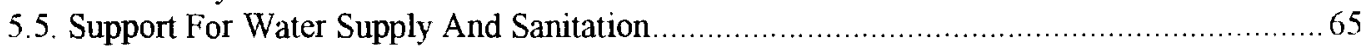

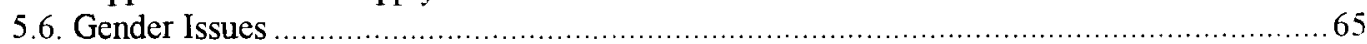

\section{Annexes}

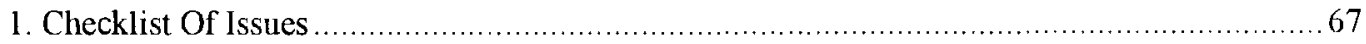

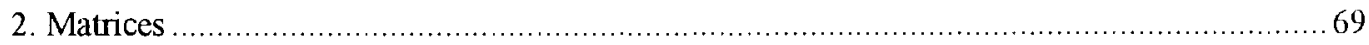

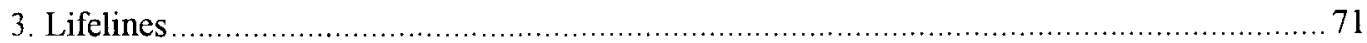




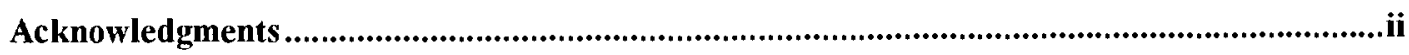

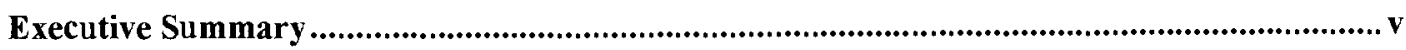

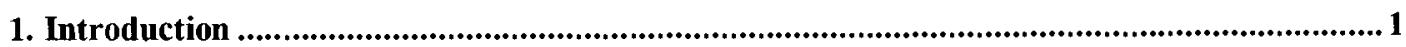

2. Background: Yakawlang And Punjao ....................................................................................4

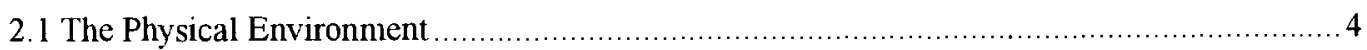

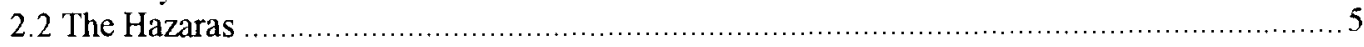

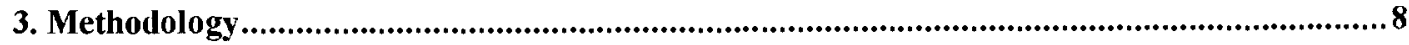

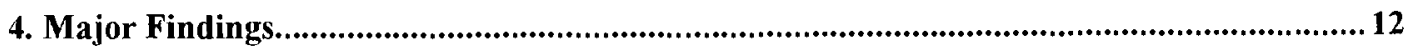

4.1 General Communities' Problems And Needs ...................................................... 13

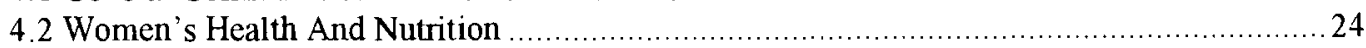

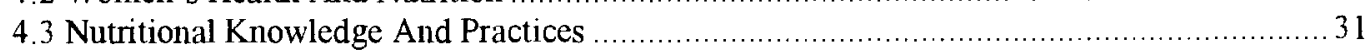

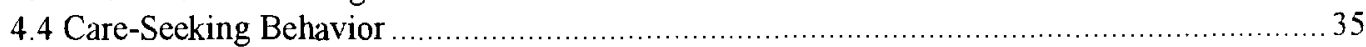

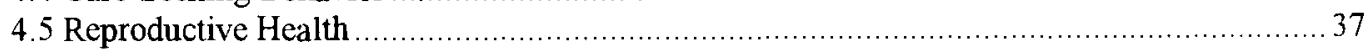

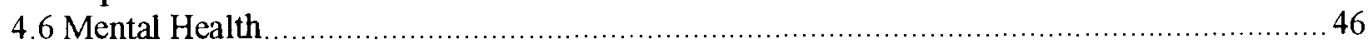

4.7 Gender Issues And Attitudes Toward Women And Girls ........................................... 51

5. Conclusions And Recommendations..................................................................................60

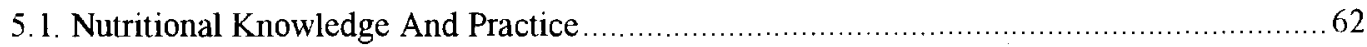

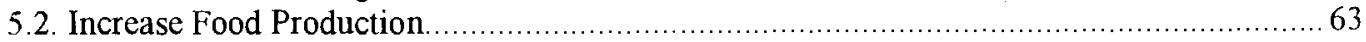

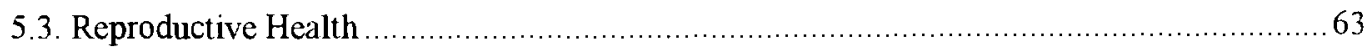

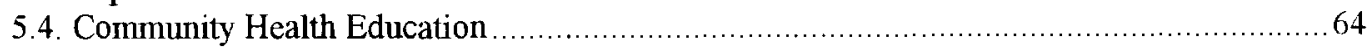

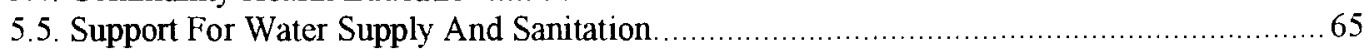

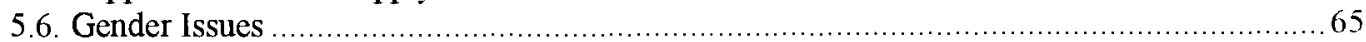

\section{Annexes}

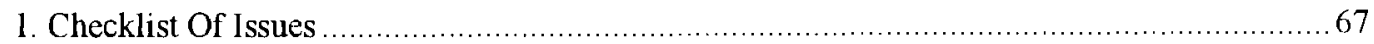

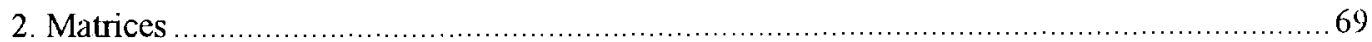

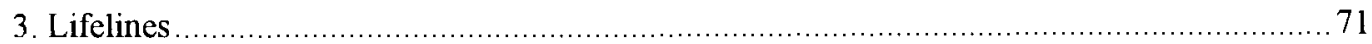




\section{Abbreviations and Acronyms}

\begin{tabular}{|l|l|}
\hline Afs & Afghanis (Afghan currency) \\
\hline ARRP & Afghanistan Rural Rehabilitation Project \\
\hline CHE & Community Health Educator \\
\hline HIV & Human Immunodeficiency Virus \\
\hline IAM & International Assistance Mission \\
\hline LEPCO & Leprosy Control Organization \\
\hline MSF & Medicins Sans Frontieres \\
\hline NGO & Non-governmental Organization \\
\hline PEACE initiative & Poverty Eradication and Community Empowerment \\
\hline PRA & Participatory Rural Appraisal \\
\hline RTI & Reproductive Tract Infection \\
\hline SC-US & Save the Children, USA \\
\hline TB & Tuberculosis \\
\hline TBA & Traditional Birth Attendant \\
\hline UN & United Nations \\
\hline UNDP & United Nations Development Programme \\
\hline UNOPS & United Nations Office for Project Services \\
\hline WFP & World Food Programme \\
\hline WHO & World Health Organization \\
\hline
\end{tabular}









\section{Executive Summary}

This is a report of a Participatory Rural Appraisal on women's health that took place in the Central Highlands districts of Yakawlang and Punjao in Bamyan Province, Afghanistan. These rural districts, among the poorest in Afghanistan, were incorporated into the UNDP Afghanistan's PEACE Initiative regions where UNOPS implements the project, Strengthening Community Self-Help Capacities. In the Fall of 1997, UNOPS began work in these districts, and was evacuated in August 1998 along with all other UN agencies after the Taliban entered the province. The PRA was planned during the winter months when the region was inaccessible due to heavy snowfall, and conducted in spring of 1998 by Save the Children-USA and The Shuhada Organization. At the time of the research, the people had been living under a crippling economic blockade of the region for one and a half years; many of the problems the people live with in the Central Highlands were intensified by the blockade, but since the region has fallen under Taliban control, the blockade has been lifted and goods are again freely moving to and from the districts.

The PRA was carried out to ascertain the population's health priorities, and to understand the knowledge, attitudes and practices surrounding women's health for planning future health sector interventions. While UNOPS was already aware of the dearth of health care services in the region, the question remained as to how the population perceived their health, and what they saw as their most pressing problems. The results of the research demonstrate that the health needs of the entire population are comprehensive, and as the report will illustrate, women suffer from a wide range of preventable ailments that go largely untreated. Caught in a cycle of persistent poverty, undernutrition, lack of safe water supply, sanitation and primary health care services, women face many impediments to improving their own and their families' health. The poor health status of women is a direct consequence of two decades of war and its attendant social outcomes, deepening levels of poverty, a virtually collapsed educational system, and a complete breakdown of the public and private health sectors. Childbearing is particularly hazardous for women in these districts where poverty, illiteracy, high fertility rates and poor maternity $\&$ 
contraceptive services are the rule rather than the exception. The natural environment presents further hardships for the people as they cope with the limitations of marginal high altitude agricultural lands, environmental degradation and long, severe winters. The political situation exacerbates longstanding ethnic, religious and political prejudices that affect resource allocation in the region. The descriptive comments of the people depict a region characterized as one of the poorest in Afghanistan that has suffered from historical neglect and discrimination.

The report reinforces the known links between women's general health, nutrition and reproductive risks. The research also took into consideration the people's perceptions of mental health, which also revealed that stress, fear and depression were commonly expressed emotions. Women named several illnesses such as musculoskeletal problems, respiratory difficulties, headache, poor vision, and goiter-all of which have possible causes rooted in nutritional factors, but they also produce problems in reproductive health, and compromise mental health.

Micronutrient deficiencies are highly evident among women and children, as nutritional habits as well as poverty and the environment influence dietary practices. Women and men both named frequent pregnancies and maternal deaths as their paramount concerns as far as women's health is concerned.

The most pressing needs that have been identified in this PRA that UNOPS can assist with are:

1. Nutrition interventions

2. Increased food production in women's domains, such as sustainable vegetable production and increased poultry production

3. Reproductive health care, including pregnancy services and family planning

4. Health education

5. Support for water supply and sanitation infrastructure

6. Women's education and empowerment

The most sensible approach to women's health in this region is to concentrate on the most essential interventions which focus on reproductive health and health education in an integrative development approach with other UN agencies in the spirit of common programming. 


\section{Introduction}

In the latter half of 1997, United Nations Office for Project Services, Afghanistan Rural Rehabilitation Programme (UNOPS/ARRP) began work in the Central Highlands of Afghanistan in the district of Yakawlang, and in mid-1998 set up offices in Punjao and Waras in Bamyan Province. The programme is an integral component of the UNDP-Afghanistan "PEACE" initiative whereby UNOPS implements the Project, "Strengthening Community Self-Help Capacities in Rural Afghanistan." The main emphasis of the project is on activities that aim to improve the living conditions and human welfare in rural areas in a sustainable manner. These activities underscore a development approach of local and community-owned solutions to local problems; rebuilding of local capacities for recovery; and strengthening community self-reliance and self-help capacities.

Initial contact with the region revealed many needs, but of the most notable were lack of social services, particularly primary health care and medical facilities. In order to understand the health priorities of the population living in this area for planning health sector interventions, a PRA (Participatory Rural Appraisal) was chosen as a method to determine the knowledge, attitudes and practices surrounding women's health. The health indicators for women and children in Afghanistan are among the worst in the world.

Conditions responsible for these indicators include longstanding poverty, political strife, the underdeveloped state of infrastructure, lack of safe water supplies and sanitation, poor hygiene practices, undernutrition, lack of education, and inadequate health services. Previous studies of the region document that the main causes of death for children include the vaccine-preventable diseases of measles, pertussis, diphtheria, polio and tetanus as well as diarrheal diseases and respiratory tract infections. National immunization figures for Afghanistan indicate that $14 \%$ of children under one are immunized - the figure for the rural districts of Bamyan is assumed to be far lower than $14 \%$ where health services are scarce.

In March 1998, UNOPS commissioned Save the Children U.S.A. ${ }^{1}$

Pakistan/Afghanistan Field Office to train and supervise a group of local women and men to conduct a participatory rural appraisal (PRA) in Yakawlang and Punjao. The PRA team was composed of Community Health Worker trainers from the Shuhada Organization, an Afghan NGO that is working in the region. UNOPS currently sponsors a Female and Male Community Health Worker training project with Shuhada in Yakawlang and Punjao. In this project, female and male trainers are stationed in villages for three months at a time where they train community health workers in community-based primary health care, TBA (Traditional Birth

\footnotetext{
${ }^{1} \mathrm{SC} /$ US has extensive experience in developing primary health care and reproductive health care programs, education programs, and microcreditincome generation progrants. SC/US is also experienced in PRA training and research methods in Afghan refugee camps in Pakistan as well as in Afghanistan. and brought their expertise to the project, their first work in the central highlands region. A successful reproductive health PRA conducted in Haripur, a longstanding Afghan refugee camp ir NWFP Pakistan, proved that sensitive issues concerning sexuality, women's reproductive health status, ethnic and gender relations were possible to explore even in the very conservative populations who reside in this camp.
} 
Attendant) techniques and basic literacy education. The participation of the Shuhada Organization also provided an opportunity to give additional training to the health educators for capacity building, and introduced them to concepts of participatory methods of community health research.

UNOPS believes that an integrative approach to women's health should address not only reproductive health, but other factors that also affect women's health such as women's social status, poverty, nutritional practices and mental health, thus viewing women in a more holistic light, inclusive but beyond their role of biological reproduction. Reproductive health care needs constitute 30-40 percent of women's health care problems, however, there is an obvious correlation between a woman's general health status throughout the life cycle, and her reproductive health risks. Clearly, the greatest threat to a woman's life in Afghanistan is directly related to pregnancy and childbirth. According to recent information from WHO, 45 women between the ages of $15 \& 45$ die every day due to pregnancy-related causes, resulting in 16,320 maternal deaths each year in Afghanistan. In addition, for each maternal death there are about 50 women who will be expected to develop chronic illnesses like pelvic inflammatory disease, genital fistulae, prolapse and incontinence. Maternal mortality also has a profound impact on infant mortality, which is estimated at $165 / 1000$ live births in Afghanistan. Infant mortality is directly linked to the state of the mother's health and nutrition, and the type of assistance provided to the mother at the time of delivery. It should not be assumed, however, that women's health considerations begin and end between the ages of 15 and 45 . The following points highlight the need for an integrative approach to women's health:

- The health of girls age 0-15 also determines the health of the young woman moving into childbearing years. Healthy mothers have healthier families.

- Nutrition is an important determinant for female health. Too few calories and nutrients produce small girls who grow into small anemic women; anemic women go on to have small babies, and suffer reproductive and other health problems.

- Differing caring and nurturing practices for boys and girls frequently have negative consequences for girls. For example, in some populations, boys often receive more health care for their illnesses, longer duration of breastfeeding, and more and better food than girls. Understanding the caring/nurturing practices for girls and boys is critical for the development and implementation of effective and culturally sensitive training programs for these communities.

- The triple burden of biological, social, and economic production creates demands for the woman often beyond her capacity to sustain these physical burdens.

- Women's health also consists of considerations around mental health. The demands of their roles of reproduction, poverty, and women's social status place stress on women that manifest in ill health.

Focusing on women's health in no way minimizes the importance of health for everyone in the community. However, given the extraordinary contributions that 
women make in their multiple roles of reproduction, families cannot afford to lose them in their most productive years. Disability and premature death among women have major implications for the entire family, and have a negative impact on child survival, economic productivity and family welfare. From the information gathered here, appropriate and culturally sensitive health sector projects can now be planned with the assistance of the community. 


\section{Background: Yakawlang and Punjao}

The PRA took place in the districts of Yakawlang and Punjao in Bamyan province Bamyan has long been a marginalized region in east central Afghanistan, for geographic as well as for ethnic, political and religious reasons. As such, it remains one of the most underdeveloped provinces in the country. Although Bamyan was largely spared the direct impact of the last 18 years of war, the physical isolation and historical neglect of the region by successive Kabul governments have contributed to the extreme economic and social underdevelopment of the region. Recent political developments have further isolated Bamyan province by the imposition of an economic and physical blockade imposed by rival political factions in early 1997, which has only recently been lifted

\subsection{The Physical Environment}

Yakawlang, the largest provincial district, is located in northwest Bamyan at an average altitude of 2,500 meters above sea level and covers 6,578 square kilometers. The main administrative municipality is known as Nayak to the local population, but is also referred to as Yakawlang on many maps, and so the two names for this town are interchangeable. Nayak is situated in a valley astride a major river, the Band-e Amir Rud, and is the primary commercial center of the district. Punjao, a provincial district due south of Yakawlang, covers 1,537 square kilometers with an average altitude of 2,700 meters. Punjao (also transliterated as Punjab) is the name of the largest town in Punjao district, located 80 kilometers south of Nayak. Its name is derived from five rivers that meet in the area around Punjao. High mountains separate the two districts, and the main road through the dramatically beautiful Shatu mountain pass linking the two districts is blocked by heavy snow from November through April. On both sides of the Shatu Pass one encounters extraordinarily rich, expansive green pasturelands that are among the best in Afghanistan. Before the war, the central highlands were considered the "meat basket" of Afghanistan, at one time producing 70\% of the meat sold in Kabul. ${ }^{2}$ Since mountains border the region on all sides, access to and from the area is only possible through high mountain passes on rough unpaved roads. A small airstrip in Yakawlang accommodates small aircraft; the principal airstrip is in Bamyan district, east of Yakawlang.

The region is shaped by the westernmost edge of the Hindukush mountain range, known as the Koh-e-Baba Mountains with peaks ranging from 3,300 meters to 5,500 meters in elevation. The climate of the area is characteristically alpine tundra, with long cold winters and short dry summers. The winter season begins by the end of September, with the first snowfall in mid-October, and from December through March heavy snow covers the land. The mountain peaks are snow-capped from October through May, and mountain passes are closed to travel until mid-May. Many of Afghanistan's rivers rise in these mountains, and human settlements are

\footnotetext{
${ }^{2}$ Hassanyar, Amir. 1998. Hazarajat Situation Report. OXFAM.
} 
largely confined to the river valleys. Vegetation on the mountain slopes is sparse and fragile, the loose soils able to support only small bushes, shrubs, and grasses. River valleys are green, and contain sparse trees like willows, poplars, and a few fruit trees, mainly apple and almond. A historical description of the landscape by Harlan (1939) is still accurate even today:

"On the ridge of Koh-e-Baba vegetation is so feeble that some herbaceous plants may be seen exhibiting their flowers within an inch of the ground, the effect is beautiful, as all the surface glows with the dwarfed herbage in a brilliant carpeting of vivid and varied colors. But not a cultivated garden vegetable is to be met with; and nowhere, except in the vicinity of running streams, and the low elevated heights are trees seen",

The river valleys are prone to flooding during heavy rains, particularly in early spring when rain melts the packed snow, which then raises river levels. Soil erosion on the slopes is a major problem, and as a result, soils are leached, and the rivers are heavily silted. Villages that are situated in valleys are highly vulnerable to flash floods and landslides that wreak havoc on the precious small tracts of agricultural lands, destroying roads, bridges, and irrigation structures. Each spring, the people are occupied with repairing the damage caused by the snow and spring rains. The region is beautiful, but the hardships the environment presents are many, and comforts are few. The people are remarkably resilient, and they have adapted well to the harsh environment over the centuries.

Agriculture dominates the region's economy, with at least $98 \%$ of the people working in farming and animal husbandry. All arable land is under cultivation for the major staple crops of wheat, barley and potatoes but there are structural limitations to agricultural activity because of the rugged topography, poor soils, and water availability. Agricultural lands are limited to narrow valleys and slopes using the most traditional farming methods which further limits the production of food. The people are faced with eking out a living from these marginal farmlands that are probably best suited for small-scale agriculture, and low density livestock grazing. Ninety percent of food production is for consumption, yet Bamyan faces persistent deficits in food production, especially cereals. It has historically mitigated this deficit by trade with neighboring provinces. The 1997-98 blockade severely interrupted trade to and from the region, leaving the people to rely on an unstable market to procure food.

\subsection{The Hazaras}

The central highlands region has for centuries been home to the third largest ethnic group of Afghanistan, the Hazaras, and the region is commonly referred to as "Hazarajat"4. Precise census figures for the population of Bamyan are not available.

\footnotetext{
${ }^{3}$ From Poladi, H. The Hazaras.

${ }^{4}$ Another ethnic group which has been absorbed into the Hazara society is the Sayeds, descendants of the Prophet Mohammad. Though they are different in appearance, they have assimilated into Hazara society.
} 
OXFAM conducted a 600-village survey in October 1997 and in March \& April of 1998 where the following data was collected.

Population Estimates of Yakawlang and Punjao

\begin{tabular}{|l|r|l|r|r|}
\hline District & $\begin{array}{l}\text { 1998 } \\
\text { Permanent } \\
\text { Population }\end{array}$ & $\begin{array}{l}\text { Iranian } \\
\text { Returnees } \\
\text { since 1994 }\end{array}$ & $\begin{array}{l}\text { Internally } \\
\text { Displaced Persons }\end{array}$ & Total Population \\
\hline Yakawlang & 100,723 & 2,000 & 4,952 & 107,315 \\
Punjao & 82,425 & 3,000 & 3,380 & 88,805 \\
\hline
\end{tabular}

Source: OXFAM Hazarajat Situation Report, 1998

The districts have experienced a growth in population over the last 5 years due to forced repatriation of Afghan refugees from Iran, an influx of internally displaced persons, and high birth rates. Over the past twenty years of conflict, many Hazara sought refuge in Iran. However the Iranian government began a repatriation policy four years ago forcing many back to Afghanistan.

OXFAM estimates a $5 \%$ per growth rate, while WFP measures a lower rate of $3.5 \%$ per annum. According to the OXFAM survey, the average family size is 7 members, and the female to male ratio is $51: 49$.

Hazarajat is an ethnic term used to describe the central highlands region and its inhabitants as early as the $16^{\text {th }}$ century. Hazarajat has never had true and officially recognized national borders, yet informal borders define the region whose inhabitants retain a discrete ethnic, and more importantly to the Hazara, tribal identity. The Hazaras have always been isolated owing to circumstances of geography, and were an autonomous group in full control of the region until the 1880 s. They consider themselves as culturally and ethnically distinct from other groups in Afghanistan; it is important to understand how some of these cultural differences are the source of significant friction with other groups in recent history, and must be recognized to understand the present situation of the Hazara people. These differences will be briefly noted below.

The spoken language is Dari, though the Dari of rural Hazaras is reported to be easily distinguished from the Dari spoken in Kabul and Herat. This dialect is known as "Hazaragi," which is described by Poladi as an arcane Persian dialect with Turkish words, as well as a number of Mongolian words, which are not found in other Persian dialects spoken in Afghanistan. Perhaps the most significant dissimilarity with other Afghan groups is the Hazara's religion; the vast majority of Hazaras follow the Shia faith of Islam, forming the largest Shiite population in overwhelmingly Sunni Afghanistan. The homage paid to their spiritual leader, the Ayatollah Khomeini, is obvious to the visitor-the presence of his photograph displayed in public spaces, storefronts, as well as in private homes is testimony to this devotion, and also signifies an alliance with Iran. The tombs of Shia Imams in 
Iran and Iraq are sacred shrines for the Hazara, and devout followers aspire to make the pilgrimage to these Shia shrines.

In the last several years of the war, Hazaras in the central highlands were united in their resistance against the Taliban militia under leadership of the ruling party of Bamyan, Hisb-e-Wahdat. The Wahdat party has political ties with Iran, which is yet another source of antagonism between the Hazaras and the Taliban, dominated by ethnic Pashtoons. These hostilities are by no means recent-relations between the Hazaras and Pashtoons have been strained since the Hazaras fought a bitter war for independence from the Afghan leadership in Kabul in 1893. This disastrous conflict sent tens of thousands of Hazara fleeing their homeland, seeking refuge in Quetta, in present-day Pakistan, and Mashad in eastern Iran. The war had long-lasting implications for Hazaras who never forgot the brutality of their defeat and subjugation. In the years following this conflict, the Hazaras were systematically neglected and excluded in Afghan government-supported social development. It is obvious to the visitor that very little has changed in Bamyan over the last one hundred years.

The village is the basic social and political unit, and consists of various numbers of households ranging from a few nuclear families to hundreds of families. Houses and shelters are constructed of sun-dried mud bricks, stones, and when available, poplar roof beams. The affluent live in spacious well-built mud brick homes with large paned windows, quite often in a 2-story structure, where the animals are sheltered in the lower portion below the living quarters. The dwellings of the poorest sharecropping tenants consist of small low-ceilinged mud houses/huts with tiny slits for windows to preserve heat in the winter, and a tiny smoke hole in the ceiling. In higher elevation settlements, these villages are almost always built with the houses attached to each other to provide maximum shelter and protection. The atmosphere in this type of house is dark and cave-like even during the day, and ventilation is extremely poor. The houses are heated by cooking indoors, and families gather in the kitchen for warmth in the long months of winter. Wood for fuel is scarce and very expensive, so the cooking and heating fuel is usually a mountain shrub known as buta, and dried cow dung cakes. During winter, animals are stabled in an adjacent room in the house.

Housing styles are obviously changing, largely due to a diffusion of styles brought from Kabul and Iran. For example, 2 generations ago, the common construction was a tiny cave-like dwelling with no windows, and a small smoke hole. One generation ago, narrow windows appeared, the rooms were larger, and now, the rooms are more spacious with large windows in the newer homes. Still, the type of dwelling is largely dependent on the socioeconomic status of the family.

It has been mentioned that the winters are long and severe, and during these months, the people are largely housebound for about 5 months. During this time; the people maintain the livestock, women work on handicrafts, and when spring arrives, all energies are invested in planting the new season's crops. When this is finished, there is a longstanding tradition of families moving up into the high pasturelands with the 
animals for the summer. Varying reports exist about the number of people who go to the mountains, but it would appear that perhaps one-third of the people summer in the high pasturelands. Most people leave their villages by June after the planting is finished, and begin to return by the middle of August to assist with harvest

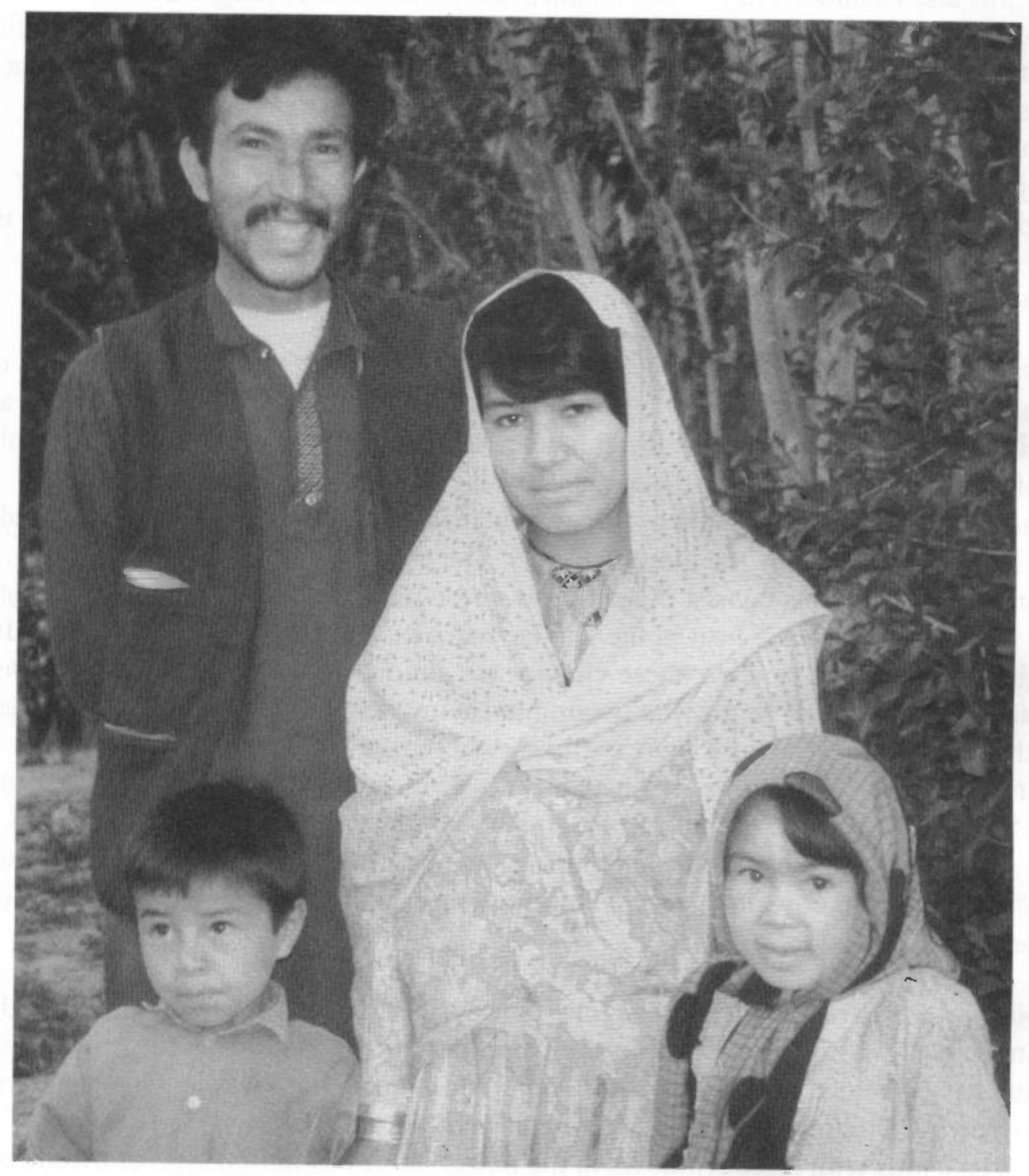

Community Health Educators involved in the PRA. 


\section{Methodology}

Consistent with the methodology of the UNDP/UNOPS Afghanistan Rural Rehabilitation Programme: Community Self-help objectives of participatory development, a PRA exercise was planned. PRA is a qualitative research approach developed in the 1980s that emphasizes the process of asking community members to identify, analyze, and prioritize their own problems. The data collection strategy utilizes teams to conduct in-depth semi-structured interviews with members of the community. The technique ranks rather than measures the problems that the community identifies and so it provides baseline data as perceived by individuals within the group, and reveals their priorities as indicators for qualitative change.

Save the Children-US (SC-US) sent a training team from Pakistan to Nayak in April 1998. The trainers included 4 Afghan nationals: 2 women and 2 men. The PRA team was composed of 17 young women and men with broad variations in educational preparation, but all had undergone an 11-month health-training course at the Shuhada Hospital and Clinic in Jaghori, Ghazni province. This PRA team had the specific advantage of ethnic similarity to the population of Yakawlang and Punjao, as most of them either come from or now reside in the region. This was the first experience with community research for the Shuhada CHEs, so SC-US presented a two-week workshop to train the group in participatory qualitative research. The workshop covered the principles of women's health, reproductive health, concepts of participatory research, interview techniques, and the 7 research tools used in the PRA. Two days were spent reviewing women's and reproductive health concepts; participatory research principles and methodology were covered for 5 days, and then the PRA tools were introduced. The Shuhada team was trained in 7 observational and interview tools to guide the discussions, many of which are particularly useful with non-literate or semi-literate participants. As each tool was presented, the team conducted field tests in the Nayak area. The PRA tools that were used were:

1. Direct observation

2. Collection of information from secondary sources

3. Semi-structured interviews using open-ended questions

4. Livelihood analysis: this tool provides a means for the respondent to illustrate income and expenditure distribution without divulging actual income

5. Lifeline analysis: the respondent is asked to recall the age at which the happiest and saddest events of her/his life occurred, and is charted along a timeline. The respondent then tells the story about each event, and the resulting narrative gives an excellent indication of the quality of people's lives

6. Daily routine diary: using symbols and pictures, the respondent and interviewer plot daily activities in a 24 -hour time period

7. Paired ranking matrix: a tool which helps the people identify and prioritize their problems

A checklist was developed for guiding the interviews (see Annex 1), which focused on the following salient points of women's health: 
- General community's problems and needs

- General health status for women and children

- Reproductive health

- Health care services

- Assessment of women's nutritional knowledge

- Mental health/well-being, gender violence

- Communities' perception of vulnerable groups

The team was divided into 2 groups that consisted of 4 women and 4 men each, who traveled to each village with SC-US staff who supervised each PRA session. When the Yakawlang study was completed, a special group of 2 men and 2 women were selected for the journey to Punjao. The river levels were still obstructing roads and the team had to walk in to Punjao from Yakawlang after they reached an impassable river crossing.

Villages were randomly selected in all cardinal directions from the main towns. Whenever possible, the community leaders were consulted before entering the village, which was possible in the towns of Nayak and Punjao. Otherwise, in the remote villages, the teams entered the villages, introduced themselves, and explained the purpose of the visit. Women and men were invited to participate in the activity, and the team waited for the village residents to assemble. Women gathered separately from the men, and the interviews took place in a variety of locations in the village: in the family room, in a formal room reserved for religious occasions, outside in the woods, or on the rooftop of a family home.

Approximately 956 women and 868 men from 26 villages assembled in groups for the PRA, and a small portion of these participated in smaller focus groups and individual interviews. Each village encounter began with gender-segregated large group gatherings. To introduce the objectives of the PRA and to stimulate group discussions, the PRA team led the exercise by applying the paired-ranking matrix to identify the respondents' perceptions of community-wide problems (see Annex 2 for examples). In this technique problems are listed and then ranked relative to each other to give a scale of significance. This usually resulted in lively discussions, and piqued the curiosity of the participants. To illustrate the matrix, the PRA team drew a series of squares in the dirt, and used various items, such as stones, plants, and flowers to symbolize the problems the group articulated. The participants appeared to understand the exercise, and would jump in to assist the facilitator with this exercise. Then, the same group was asked to repeat the process for women's and children's health problems. Following the paired ranking matrix exercise, the women and men were then divided into smaller focus groups and individual interviews where the topics were narrowed to the specific issues of women's health. After the PRA was completed, translated, and the data analyzed, secondary sources were consulted to help explain, clarify, and confirm some of the trends that emerged (triangulation). Secondary sources are interspersed in the presentation of the findings. 
The PRA training began in late April 1998, and the interviews were completed by the end of May. Political circumstances in the study area have changed since this PRA was completed, and the people are now living under Taliban control since the Taliban occupied the central highlands in August 1998. It remains to be seen how this will affect the lives of the people.

\title{
The Shuhada PRA Team
}

This PRA was conducted by a group of local community health educators who had broad levels of educational preparation--the average level of education for females was grade 6. The group had no prior exposure to formal research of any type. Given these circumstances, the CHEs responded extremely well to the training and guidance of Save the Children staff, largely due to their own eagerness and goodwill to participate in the project.

\begin{abstract}
All of the interviews solicited very rich information, perhaps reflective of a local tendency for storytelling in a largely illiterate group. The CHEs proved to be skilful in obtaining basic health information, however their interview skills were not highly developed in asking probing questions, developing the topics to a higher level of discussion, and stimulating greater in-depth discussion on specific on issues such as weaning practices, food habits, gynecological problems, gender violence and mental health. To a certain extent, the relative youth of the team may have prevented them from asking probing questions of an elder out of respect for her/him. On the other hand, the respect that the CHEs were shown because of their status as educated health workers was also important to the success of this research. The ethnic similarity and ability to speak Hazaragi, the local dialect, was an important factor in communicating with community members.
\end{abstract}

This was a unique opportunity to provide training to the CHEs that they otherwise would not have been exposed to. Now that they have had the benefit of contacting communities and exploring their problems from a participatory research approach, rather than as teachers, it would be expected that their understanding of the health education needs has improved. Further monitoring and evaluation of the CHEs will be needed to ascertain if this is the case. The men in particular are now incorporating maternal health needs in their health education interventions for men, which is an important outcome for the CHEs and their beneficiaries. 


\section{Major Findings}

The findings of the PRA are presented in the following way. First, the community problems people identified will be presented in terms of the priority assigned to them. Important insights can be gleaned from understanding how the population perceives their overall problems, and how these problems have a direct or indirect link with health. Their responses serve to inform the more specific discussions on women's health in the later sections. Next, the findings on women's general health and nutrition, reproductive health, and care seeking behavior will be presented. Mental health is then examined together with gender relations, since the social status of women evidently has implications for mental health. The information that the people shared with the team is rich in description, and the stories they told give an indication of the difficulties of life in this harsh mountain region. The PRA team and their supervisors worked hard to document the anecdotal information that the villagers shared, and because of the poignancy with which the women and men related their stories, their direct quotes will be presented extensively.

The researchers were received well in the villages, and the gracious hospitality shown by the people was extraordinary. The teams were treated with respect as well as a certain amount of deference - educated persons are shown the respect of the people. Although the team members live in the region, their goal was to observe the districts and its inhabitants as if for the first time, as their PRA trainers advised. The following is an example of direct observation by one PRA team member upon entering the village of Chehdrei in Yakawlang

"People in Chehdrei are so poor. They wear rags over rags to prevent the cold. They have chapped lips and cracked hands. Some people, both children and adults, have skin infections around the corners of the lips. The children have rosy and cracked cheeks. Some look very healthy and many look malnourished because they are so thin. Children wear plastic shoes, and they wear socks and caps of all sorts. Some women were busy making cakes from cow dung. There were cakes pasted on the walls everywhere. Their houses are small and many people live in one room. People were surprised to see us and wanted to know where we are from and what we were doing here" (13 May, 1998)

In an another example they wrote that:

"Dara-I-Ali lies between two very tall mountains and there is no land for growing crops. People's personal hygiene is poor, their clothes are torn and old. Most share rooms with animals. There are no latrines and most people go to open fields for defecation. There is a river from which people take water for both drinking and washing. Most people looked very weak. Most were sick and a few were coughing blood. Most children have skin diseases. The houses are small, dark and without windows. The team met a family that was living in the tandoor [tandoor 
khana-cooking room] due to cold. No school was present. There are no trees in the areas yet in some compounds we saw piles of freshly cut wood. There are no grazing fields in the area, the animals cross the river to go to grazing fields on the other side" (9 May, 1998)

These observations by the PRA team document some of the difficult circumstances of life in the central highlands, and the living conditions as the team found them. During the PRA, women from the villages frequently asked the team members about many illnesses they and their children were suffering from. For example, a mother brought her two-year-old son to be seen for severe burns to about $20 \%$ of his body (he had been released from hospital the previous week); another mother asked about her infant who obviously had an umbilical hernia; a young woman asked about her symptoms of a large inflamed lymph node under her jaw (mastoiditis) and other symptoms resembling TB; and quite a few skin problems were presented. This was a difficult situation for the team, who could do nothing but advise them to try to see a health care worker, and provide some basic health education during the interviews.

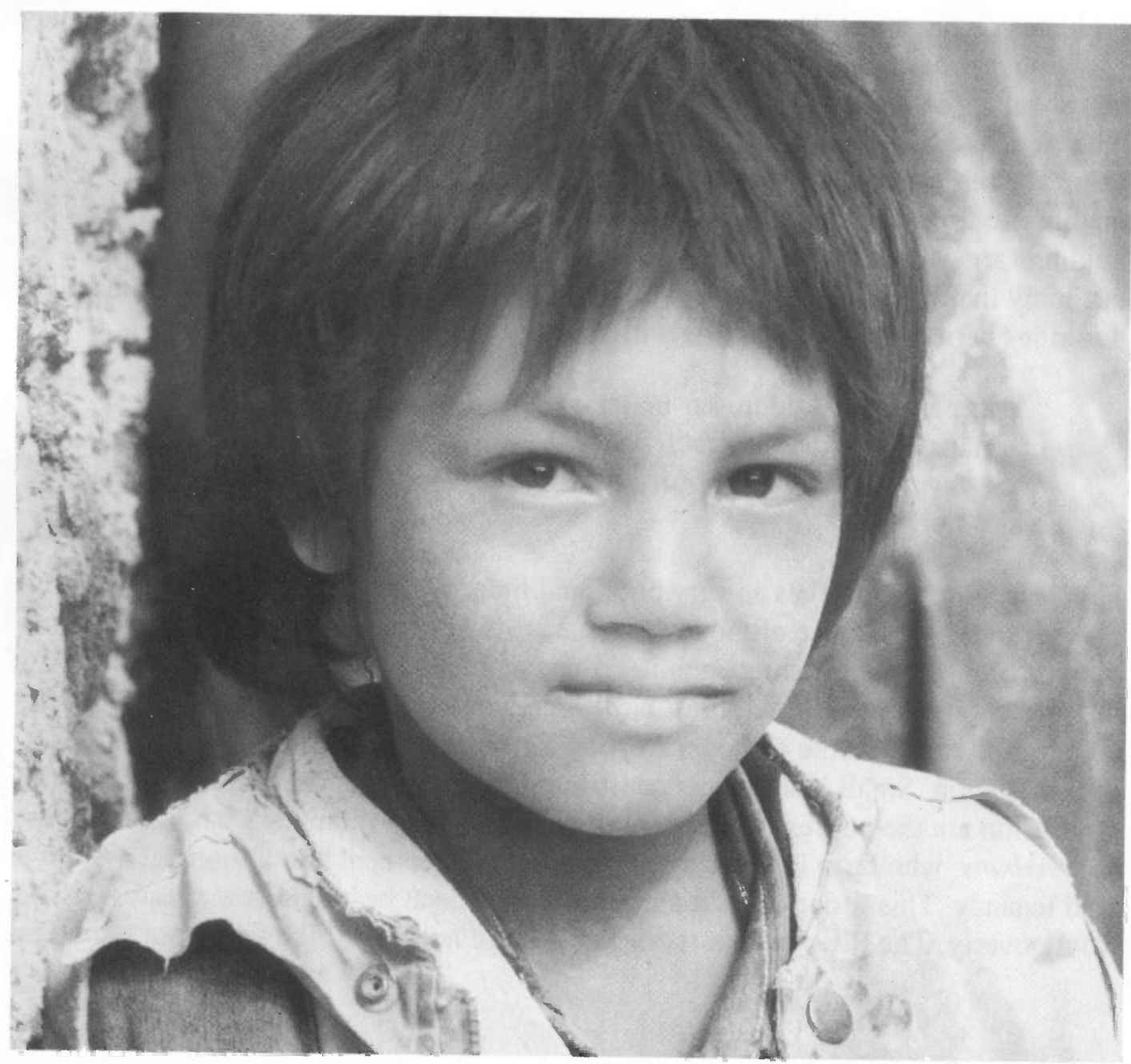

A young boy with chapped cheeks 


\subsection{General communities' probleíms and needs}

There was general agreement among the people in both districts that the following problems were their greatest concerns. The problems that the people identified were

- Poverty and unemployment

- Poor health/iack of health care

- Food shortages

- Bad road conditions

- Floods

- Illiteracy/lack of schools

- Animal health/diseases

\subsubsection{Poverty and Unemployment}

"...You will not be able to find poorer people than us on this earth"-group discussion with men, Punjao

Women and men both agreed that poverty and unemployment are the greatest problems facing them. This was the case for Yakawlang as well as Punjao, and there was an overwhelming sense of hopelessness that any of these problems could ever be solved without outside assistance. The people were living with an economic blockade, and livelihoods \& trade patterns were considerably disrupted for over a year. The region's livestock trade was the most negatively affected due to the inability to transport the animals out of the area for sale for two years. Livestock holdings are at an all-time low, which has cascading effects through the entire economy that is heavily dependent on livestock and their products. One woman describes her economic hardships with a metaphorical expression:

"Agar pai put mekunum sar maimana, agar sar put mekunum jan maimana" (If I cover my feet, my head becomes uncovered and if I cover head, my feet become uncovered, such is life ")-50-year-old woman, Yakawlang.

People refer to themselves as very poor, and indeed, they do live in conditions of severe poverty and some of the lowest standards of human development anywhere in the world. Distinct socioeconomic groups make up the complex rural economy of the Hazara. ${ }^{5}$ Landowning families in the area with sufficient resources to comfortably feed, clothe and educate their family members comprise about $10 \%$ of the population. Small landowners constitute $60 \%$ of the population, and $25 \%$ of the population are the poorest segment of the peasant class of landless laborers known as dehkhans, who farm lands in a sharecropping agreement under a feudal system of land tenancy. This group leads a marginal existence at best, and is at greatest risk from poverty. The PRA team interviewed a large number of the very poor dehkhans.

\footnotetext{
'For a detailed livelihoods, see report by M. Semple produced for UNOPS, Strategies for support of sustainable rural ivetihoods for the central highlands of Afghanistan. Pattan Development Organization, Islamabad 1998.
} 
"I have no land, no livestock, and the children are hungry. It is so difficult to buy wheat. We eat potato for all meals, and I don't know what to do. My children cry for bread before going to sleep. Ifeel like committing suicide because I cannot bear to see them in such a condition"-male, no age given, Yakawlang.

Ten women interviewed were widows who depended upon khairat, or charity, provided by neighbors and friends. Nearly half of their income was from charity in the form of food, old clothes and money. In addition, some widows have children working as daily laborers and/or farmers. One widow in Panjao said:

"I am only living for my children otherwise I would have preferred death to this life. My two small sons work as laborers and sometimes as dehkhans and bring some income which is not enough. Most of the time we get "khairat" from our neighbors and kind people. The happiest day is when we have one full meal. May Allah bless the villagers who are kind enough to give khairat, food and old clothes for my children and myself",

The following description of a typical dehkhan household is provided by Semple:

- They live in a single room hut provided by the landlord

- The bulk of the food comes from a one-quarter share of the wheat they cultivate for the landlord

- Their diet mainly consists of bread eaten with salt, with little else

- They own about five goats and two mountain cows, sale of which yields their only cash income which is spent on grain to supplement their one-quarter share

- The men are obliged to perform labor on infrastructure projects as ordered by the local Islamic Council and women are obliged to supply free labor to the household of the landlord

Repatriated refugees from Iran have found great difficulty in establishing themselves in the local economy, and felt that they were better off in Iran as refugees. These people are looking for a way to leave Bamyan, either to go to Pakistan, Iran, or to southern Afghanistan.

Livelihood analyses provide information on the distribution of income and expenditure patterns. Livelihood analyses of thirty-three participants ( $70 \%$ male) were examined to determine a rough estimate of the distribution of household income and expenditures. The total number of household members represented by participants of livelihood analysis exercise is approximately 250 . Each household has on average 7.8 family members; the average age of male participants is 45 , ranging between 15 and 63 , and the average age of female participants is 37 , ranging between 20 and 65 . 


$\begin{array}{lcll}\text { Income } & \% & \text { Expenditure } & \text { \% } \\ \text { Farming } & 46 & \text { Food } & 54 \\ \text { Daily labor } & 17 & \text { Clothes } & 17 \\ \text { Handicrafts } & 11 & \text { Health } & 10 \\ \text { Livestock } & 9 & \text { Fuel } & 8 \\ \text { Shepherds } & 6 & \text { Education } & 5 \\ \text { Teacher } & 2 & \text { Debt servicing } & 2 \\ \text { Work in organization } & 2 & \text { Animal care } & 1 \\ & & \text { Personal hygiene } & 1\end{array}$

Overall, the results of the livelihood analysis describe a picture of a poverty-stricken community that spends over half of its income on food, and meets the remaining needs as best as it can. Men commented that unemployment has increased over the years. The $2 \%$ of people who are teachers have not received any salary for almost one year. Sixty-two percent of the families interviewed for the PRA are dehkhans or daily wage laborers, who spend $60-70 \%$ of their income on food, between 12 and $19 \%$ on fuel, and between 12 and $25 \%$ on clothes.
"My life is like a dog, there is no source of income. I work from morning to evening and when I get back home, the other family members ask me to go to the bazaar to buy food. I get upset because I cannot buy ghee, rice or lentils. Even for washing we only use water and for two weeks do not change our clothes because we cannot afford soap. Sometimes we buy Pakistani soap because it is cheap. Women wash themselves with yogurt and only after 14-15 days they wash their hair with soap"-22- year-old male shepherd.

More families are finding it necessary to borrow money or sell livestock simply in order to purchase enough wheat to survive the winter. Indebtedness is becoming a way of life for many people. The livelihood diagrams indicate that about $3 \%$ of the respondents, including one woman, work as moneylenders (locally called sood khor, literally "interest eater", a pejorative term for moneylenders). One fifty-year-old woman who is a moneylender in Abdara, Panjao related:

"I am not happy with this life as I am in debt all the time. I have to return huge amounts of money to people from whom I borrow money and then I give loans to other people. My income is the "faidah" (profit) that I get on loans. People return loans very late. They do not understand that I have to return the money back to people in time, otherwise they increase their profit also. I have no lands or livestock. I have two sons who work as daily laborers" 
Men are the primary income earners for all families. It is uncommon for women to work outside of the home unless the family is very poor. Lifelines identified many young girls who worked as shepherds and maids. Older female laborers make dung cakes, spin wool, and clean houses for other families, usually in exchange for food. As in many parts of Afghanistan, women's economic activities (paid or otherwise) revolve around poultry, handicrafts such as wool spinning, gilim weaving, knitting, and embroidery-skills which are highly valued by all members of the family.

"I spin wool, and get 2000 Afghanis and I buy oil and salt with the money I earn, and sometimes we knit socks and sell them to earn money"--50-year-old woman, Yakawlang.

These handicrafts provide some income, but no more than about ten percent of the total family income, and is essentially produced for home consumption. The unavailability of or inability to purchase raw materials for handicrafts was a frequent complaint voiced by both men and women. Lack of wool was confirmed and explained by Michael Semple whose research revealed significantly reduced herd sizes in the region due to the difficulties of the crossing the blockade, the high cost of fodder for the winter months, and degraded range lands ${ }^{6}$. Lower animal holdings are now having a marked impact on the livelihoods of the people, and now women's small opportunities for income generation are being lost. Another shortage women complained about is of the silk thread used for their fine embroidery.

"We don't know any kind of solutions for these problems and we want another organization to help us. We know how to weave carpet and gillam and how to knit sweaters and shawls. We are poor and we cannot buy the raw materials, so if any organization can help us we will get busy with our work"--group discussion with 7 women.

In spite of the economic hardships, women are managing to run the household, to cut back, and to find ways of managing.

\subsubsection{Poor Health/Lack of Health Care}

"When we get very sick we go to the Iranian hospital, it is 10 hours away from our village. Some people who have severe illnesses die on the way to the hospital, and if they make it there they don't give good medicine. There is only one shop in our village, and they sell only one medicine. For most of the diseases they use the same tablet"--from small group discussion with women, Yakawlang.

Without exception, every group identified health concerns, for example, poor general health status, lack of modern health care, long distances to health care, and high cost of medicine as the second most serious problem following poverty The interviews revealed that when people are ill, they do not seek care unless the illness

\footnotetext{
${ }^{6}$ Livlihood Assessment in Hazarajat, performed by Michael Semple. consultant with Pattan Development Corp. Mr. Semple is an expert in the region. having been the central highlands regional manager for OXFAM.
} 
becomes quite severe, if at all. Most people rely on traditional medicine as a first resort to care or, depending on the type of illness, they visit a shrine or the mullah. They often go to the chemist and purchase whatever medication is available or affordable.

"There is no hospital, no doctors. If the sick person recovers on their own, that is fine, otherwise they die. The hospital is 7 hours away so most people go to the shrines and use home remedies" - group discussion with 5 women, Yakawlang.

Health services are meager in these 2 districts, and are sponsored by a few international and local NGOs - there are no government-supported health care facilities in either district. At the time of the PRA, the following access to modern health care was provided by:

- MSF-Belgium sponsors a full service hospital in Punjao, including a fixed vaccination center (run by IBNSINA), supplementary feeding unit for malnourished children, and a maternal child clinic. The medical staff consisted of one female physician, one male surgeon, one nurse midwife, and 4 male nurses.

- Leprosy Control Organization (LEPCO) provides a free treatment clinic for tuberculosis and leprosy sufferers in Yakawlang as well as in other districts in the highlands. Leprosy is present in the region, but is on the decline

- The International Assistance Mission (IAM) has had a small but important presence in the region for many years. A female physician, Dr. Lena Kaartinen, lives and works among the people, and her mission is community health education and TBA training

- OXFAM, which has been active in Yakawlang, Punjao and Waras for 8 years, has suspended their health care services projects for the time being. They are focusing on environmental sanitation, village-based community health education, promoting traditional herbal medicine and vegetable gardens.

The Iranian Red Crescent operated a hospital in Nayak and a small out-patient clinic in Punjao. The Nayak facility had an in-patient capacity of 10 beds, surgical services, and 2 clinic days a week for women and children. Since the Taliban took Mazar, the Iranians evacuated the region, and now the hospital is barely functioning Fortunately for the population of Yakawlang, Shuhada Organization is preparing to assume responsibility for re-opening and staffing the hospital now that the Iranians have evacuated.

Medicine is purchased from the local chemist. There are four chemist shops in Yakawlang, and 3 in Punjao. The chemists are now getting their supplies from Iran and Russia; the usual supply route from Pakistan via Ghazni was not accessible during the blockade. They complained about the high cost of medications, and the unavailability of some drugs, such as vitamins, intravenous solutions, many classes of antibiotics, and bandage dressings. One Yakawlang chemist stated: 
"What we need is a well-equipped clinic-some competition for the Iranian hospital. They examine the patient, and charge Afs 20,000 in fees. Then they give the patient 3 or 4 tablets of medicine. That is maybe worth about 5,000 Afs of service but they are charging 20,000. They staff the hospital with doctors with low training who are forced to come and work in Yakawlang - they don't want to be here"

Yakawlang respondents also expressed dissatisfaction with how they were treated at the Iranian hospital compared with Punjao respondents who were satisfied with the services provided at the MSF facility. Yakawlang residents also expressed some cynicism about the presence of the Iranians in Hazarajat, and this may have played a role in their distrust of the services provided at the Red Crescent Hospital. A common complaint about the hospital in Nayak was the high cost and poor quality of medications. The doctor there would see the patient, give a few tablets of medication, and give them a prescription that they would have to fill in the pharmacies in the bazaar. Few of the people could afford to purchase the medicine Payment in kind was also taken and one woman said, "We give meat, eggs and milk to doctors but they still do not give good medicines"

A physician from the Iranian hospital was interviewed, and the following is an excerpt from the interview:

"... The Out-patient Department is doing the major part of the work. Because the clinic is small, we reserve 2 days a week for women, 2 days a week for men, I day for children, I day for military personnel. In emergency cases, the patients are seen and treated at any time but if the people come outside of the reserved clinic days, they are not given medicine free, they are given a prescription to purchase at the bazaar. In the Out-patient Department, an average of 120 children are seen on children 's days, 118 women are seen on women's days, and are given medicine free of charge. Routine women's problems are seen by murses with the consultation of the doctor. The people complain about lack of medicine. Of the patients who come to this hospital only a small number of them have serious problems that deserve medicine. The rest are minor problems that don't require medicine and we just give them a few tablets. They expect that they should get medicines like other patients. Patients who come on non-clinic days get a prescription and they have to go to the bazaar to buy the medicine. Today 20 women came to the hospital, but it was not their clinic day and we gave them a bazaar prescription and they were very disappointed. Because the population of Yakawlang is large, and there is only I hospital, we cannot meet the needs of all the people, especially in hot weather. In fact, most people from Hazarajat come here. People complain about this hospital. But I tell you, for the people who are suffering badly from serious illnesses, we try our best to help them" 
The people of Yakawlang were more concerned about travel time to health care than were Punjao residents - Yakawlang is nearly 4 times the size of Punjao, and distances are much greater from the outer reaches of the district to the hospital. Punjao's population is denser than Yakawlang, and distances between villages are not as great, so it is somewhat easier for more women to seek assistance.

Many people reported that their health problems are also caused by bad water. They cite that they are sick from stomach problems, dysentery, skin problems, and said that it is not uncommon in the summer months to have cholera and typhoid epidemics. The extent of these epidemics was not possible to confirm aside from anecdotal reports. Water supply and sanitation are primitive; few wells were seen in the villages away from Nayak and Punjao. Women were observed washing their dishes in and taking water from irrigation ditches, and the children's hands, feet and faces were soiled with layers of dirt.

"I can't keep the children clean. When I came here from Iran to this village, I could not get used to the dirt. I can't keep anything clean, the dirt, it is everywhere" -individual interview with 24-year-old woman, Punjao.

\subsubsection{Food Shortages}

"We have access only to oil and wheat, and there is nothing else to use. Our food is boiled water and bread"-group discussion with 5 women, Yakawlang

In the paired ranking matrix on general community problems, food was identified as a conspicuous concern for everyone. In every village, for every family, people were suffering hardships related to food costs or food availability in all but the most wealthy groups. Bamyan is a food deficit region in the best of times-WFP estimates that the area suffers from an annual 3,000 metric ton wheat deficit. The usual market mechanisms for compensating for food deficits have been severely disrupted by the war. Food shortages are due to conditions of poverty, uneven distribution and diminished purchasing capacity rather than an actual shortage, even in spite of the blockade. However, the hardships of the people were made even worse last year when an early frost damaged the harvest in fall 1997, happening at the worst possible time for the people.

Reports of food shortages and malnutrition in Hazarajat brought on by the blockade prompted WFP to conduct a vulnerability analysis to determine the food needs of the region in early 1998. The analysis revealed the following food procurement patterns for the majority of the population: people meet $35 \%$ of their food needs from their own agricultural production; livestock production comprises about $5 \%$ and wild food collection fills another $5 \%$. This means that at least $55 \%$ of minimum food needs must be purchased from the market. With an unstable economy, livelihood disruption and a high proportion of landless laborers, the dependency on markets for food procurement creates more vulnerability. With runaway inflation 
estimated at $400 \%$ from 1997 on food prices, combined with reduced income potential due to the blockade, the majority of people are at great risk from food insecurity. The region as a whole, however, was not found to be experiencing widespread famine and malnutrition. Nutritional surveys in the region by WFP as well as UNICEF and ACF (Action Contra la Faim) identified small pockets of malnutrition confined to isolated villages in Hazarajat. Operating under the assumption that the prevailing economic conditions remain the same, the study concluded that $85 \%$ of the population can be termed "vulnerable", and that the marginal groups will be at risk of clinical malnutrition

A market survey conducted in early June found a complete absence of vegetables and fruits (including onion, garlic and tomato) in both districts. The bazaar shops' inventories of dried fruits and vegetables were exhausted and many of the shops were closed while the shopkeepers traveled the long and arduous road to Ghazni to procure supplies. Many people are eating barley bread with boiled water for their meals.

"We are very poor. My sons are dehkhans and bring very little income. We can not even buy vegetables. We eat barley when wheat has finished, but since last year we have not eaten wheat or even barley. We only eat potatoes provided by a relief organization. Life is difficult as there are too many family members to eat-sometimes we sleep hungry"-45year-old widow, Yakawlang

Respondents consistently admitted that they could not afford to feed large families; this was especially noted among landless laborers. One woman reported that people are now marrying off their daughters at younger ages, as early as 11 , because families cannot afford to feed all of the family members. People admit that food consumption for the entire family is decreased. This ration cut also affects pregnant women who do not eat food of good quality and quantity. One man in a group discussion in Panjao said:

\section{"Even when mothers are delivering children, we cannot afford extra food for them"}

Several men reported that people were leaving the region in greater numbers owing to hunger, however, the scale of out-migration is not known at this time. WFP heard conflicting reports of the number of people leaving the area, and returned Iranian refugees expressed the desire to leave Hazarajat. Many would like to leave, but cannot afford the travel.

"Up to the present time, 35 families have moved from this area. They migrated because of hunger. Our major problem with families is health of mother and children, we are always sick. We are hungry, and hunger is a kind of sickness" group discussion with men, Yakawlang 
Given the current situation of food production deficits and livelihood disruption, food security is a significant concern for this population. People are preoccupied with securing enough staples to get them through the winter, and there is a reported out-migration of unknown magnitude due to food insecurity. In addition to the lack of nutritious foods available, poor understanding of what a healthy diet consists of is also evident, and symptoms of micronutrient deficiencies were identified.

Now that the Taliban have moved into Bamyan, and resistance factions have either surrendered or disappeared, the blockade has been lifted, thus alleviating many of these concerns pertaining to livelihood and food security that existed at the time of the PRA.

\subsubsection{Poor road conditions}

Fifty percent of the people identified road conditions as a major problem in the region. Distances between villages are great, particularly in Yakawlang, over rough unpaved roads. It is not unusual for roads to run parallel to rivers down narrow valleys, and the roads traverse these rivers in numerous locations. During winter, heavy snowfall closes the roads and mountain passes for up to 5 months and in the spring, the snowmelt raises river levels, making them impassable. Women must travel these roads with their husbands and children to seek health care either by foot or by donkey, and the journeys are long and arduous. Many people are thus discouraged from seeking care even in emergencies. Transportation was also identified as a problem for families who must hire a donkey or horse for transportation.

\subsubsection{Environmental Hazards}

Men and women both identified floods as a major concern because the spring brought recent damaging floods. In Punjao, the PRA team visited a small village whose residents were in despair over the effects of a recent flood. One third of their best farmland lay under 1-2 meters of rocks and mud that washed down from the valley, which also destroyed 3 homes. The planting had just been completed when the flood occurred, and many of their crops not under debris were washed away.

Environmental degradation from deforestation, overgrazing, and inefficient monocrop farming techniques on slopes contribute to soil erosion, and flood hazards. Villages located near the mouths of valleys are particularly vulnerable to flash floods and landslides. Not only do floods deposit large debris over the limited farmlands, they wash away precious soil and destroy irrigation structures which have to be repaired, causing further hardships. Women's workloads are increased when they work to help clear the land of the debris and heavy rocks. 


\subsubsection{Illiteracy/lack of schools}

"We have no objection to school for both boys and girls. The lack of

schools, teachers and materials keeps us from educating our

children"-group discussion with men, Punjao.

The vast majority of women are illiterate, with only one or two women per village who have any literacy skills. Figures on literacy are not available for the population, but it is evident that the majority of adults are illiterate, and more women are illiterate than men. The majority of schools that are open and functioning are for boys, but these schools function with little to no support-many teachers' salaries had not been paid for one year, and a lack of materials and textbooks are common complaints. There was consensus across both district and gender categories that people value education for girls as well as boys.

"We have a school for boys and girls. The highest rank for girls is up to 5th class, and for boys up to 12 grade, and for higher education they go to Bamyan. It is coeducational. The school needs chalk and paper which are the major problems. [Three of the women said] In this area, some of the schools belong to the chief of the village, they expel our children and admit their own relatives and children"--group discussion with women, Yakawlang.

The following information on district schools is available:

\begin{tabular}{|l|l|l|l|l|}
\hline \multicolumn{5}{|l|}{ Education Statistics in Yakawlang and Punjao } \\
\hline & No. of & Female & Male & Total \\
District & Schools & Students & Students & Students \\
Yakawlang & 30 & 2644 & 5132 & 7776 \\
Punjao & 20 & 289 & 2364 & 2653 \\
Total & 50 & 2,935 & 7,496 & 10,429 \\
\hline
\end{tabular}

Source: UNOPS Education Programs in the Central Highlands

Even though the women and men say that they fully support equal access to education for boys and girls, a clear bias towards education for boys exists. For example, while the above table indicates the existence of female students, in reality, most of the girls attend school only for grades one and two. There is an acute shortage of buildings for schools, but even more importantly, there is a lack of trained teachers of both genders. In a group discussion with women in Yakawlang, the women commented:

"The schools are closed, there is no money to pay the teachers. We are all in favor of boys and girls education. No mother or father forbids education"-group discussion with women, Yakawlang.

The interviews revealed that many children are removed from school because of the need for their labor at home, particularly girls. Returned Iranian refugees reported that they had easy access to education in Iran, and are eager to provide their own children with schooling. One woman in Yakawlang, who was raised in Iran, now 
living in Afghanistan, asked for books so that she could at least begin to teach the children how to read and write.

"The fundamental problem for our mothers in this village is illiteracy. We don't know anything about cleanliness and how to keep our children clean, that is why we get sick"-group discussion with women, Yakawlang.

\section{Summary}

The above problems identified by the people places the women's health and gender issues presented below into context. Although the problems were presented separately, none of them can be viewed in isolation, as the net effects are all interrelated. Caught in a cycle of persistent poverty, undernutrition, lack of sanitation and primary health care services, women face many impediments to improving their own and their family's health. The natural environment presents more hardships for the people as they cope with the limitations of the agricultural lands, natural hazards, environmental degradation and severe winters. The political situation exacerbates longstanding prejudices that will continue to affect resource allocation in and to the region. Their comments depict a region characterized as one of the poorest in Afghanistan that has suffered from historical neglect and discrimination. Each of the above problems has significant implications for health for the people of this region where international assistance has been limited, and the people's expectations of the new presence of the UN are high. The Hazaras are eager to improve their situation, and expressed a willingness to participate in activities that will advance their people.

\subsection{Women's Health and Nutrition}

\subsubsection{General health and nutrition problems}

All women were asked to identify their health problems and most common illnesses in a ranking matrix exercise. Twenty five matrices were analyzed, and with few exceptions, women reported a consistent list of health problems and physical complaints. There was no significant variation of health problems between the two districts. Some non-specific complaints are difficult to distinguish from reproductive health problems such as back pain and stomach problems--these symptoms will be explored in both general and reproductive health categories. The symptoms were reviewed and interpreted by 2 female physicians who are well acquainted with the health practices and beliefs of rural Hazara women, Dr. Sima Samar, Director of the Shuhada Organization, and Dr. Leena Kaartinen, of International Assistance Mission.

\subsubsection{Musculoskeletal Complaints}

"We are always sick. There are no doctors, we use the traditional methods for treatment but it doesn't work. We are busy doing housework 
and working on the land. During the day we don't notice the pain, but during the night we feel the pain strongly and we cannot get to sleep until the morning"-group discussion with 7 women, Yakawlang.

Women identified at least 3 major categories of pain: back pain, non-specific bone and joint pain, and leg/foot pain. Seventy-five percent of the groups named these body aches and pains as their most common problems and two groups referred to rheumatism. Dr. Leena has also observed the high incidence of women's body aches in her work. She suggests that the musculoskeletal problems are often caused by women's strenuous and long days of physical work. This is compounded by osteomalacia (thinning and weakening of the bone) due to calcium or vitamin D deficiency; frequent pregnancies; long duration of breastfeeding; and the tendency to fast from milk and milk products as a treatment for a wide range of aches and pains. Common treatment for these pains include massaging mustard oil and/or "used mobile oil" in the affected area and sitting in the sun for one hour to relieve the aches. When the family can afford medications from the bazaar, they use "tablets" (usually paracetamol), and one woman reported taking opium for pain.

"Most often we have skin problems, back ache, leg problems and headache. We have gotten to the point that the worst disease for women in this area is back and leg problems"--small group discussion with women, Yakawlang.

A major contributing factor to the pains women are experiencing is a woman's long hours of daily household labor from a very early age. Below are three examples of daily routine diaries that illustrate the typical day in the life of women. 
Examples: Daily Routine Diaries

\begin{tabular}{|c|c|}
\hline \multicolumn{2}{|c|}{ 21-year-old married woman, Yakawlang } \\
\hline $\begin{array}{l}\text { First one awake, } 0500 \\
\text { pray } \\
\text { make bread dough } \\
\text { cleans oven and kitchen } \\
\text { collects water } \\
\text { bakes bread } \\
\text { make dung cakes } \\
\text { washes dishes } \\
\text { spins wool } \\
\text { gillam weaving } \\
\text { milks } \\
\text { collects fodder for animals } \\
\text { pray } \\
\text { cook } \\
\text { eat dinner } \\
\text { pray } \\
\text { sleep, it is dark }\end{array}$ & $\begin{array}{l}\text { "My husband is a soldier in Bamyan and does not live at home. I am } \\
\text { not happy, I have no decision making powers. If I say something, they } \\
\text { all disagree. I would love to learn how to read and write but there is } \\
\text { no one to teach me. I have to do all the hard work because I am the } \\
\text { youngest. My mother-in-law tells me, "We have not brought you in to } \\
\text { the house to get fat, you have come to do hard work" } \\
\text { I know nothing about where the money I earned for spinning and } \\
\text { weaving goes. I have been married for } 9 \text { years, and have never worn } \\
\text { any new clothes since living in my husbands house. If I get tired of } \\
\text { doing hard work, I have no choice, I have to do it. If I get sick, I still } \\
\text { have to work. Now I have back and kidney pain so I tie a belt around } \\
\text { my waist, no one believes that I am ill" }\end{array}$ \\
\hline \multicolumn{2}{|c|}{ 26-year-old married female, Punjao } \\
\hline $\begin{array}{l}\text { wakes up, sunrise } \\
\text { pray } \\
\text { mix bread dough } \\
\text { bakes bread } \\
\text { milking animals } \\
\text { washing up at river (dishes) } \\
\text { breakfast } \\
\text { collect fodder, fuel } \\
\text { lunch } \\
\text { prayers } \\
\text { gillam weaving } \\
\text { farm work with husband } \\
\text { fetch water } \\
\text { spinning wool } \\
\text { cook, dinner } \\
\text { prayers } \\
\text { sleep, nightfall }\end{array}$ & $\begin{array}{l}\text { "I do all the work alone. When I get sick, my mother in law makes } \\
\text { bread dough and she calls someone else to bake it. Spinning provides } \\
\text { some income for family. Food we eat is only nan, tea and dogh } \\
\text { [buttermilk] because we are very poor. My husband is a farmer for } \\
\text { others and has no proper income" }\end{array}$ \\
\hline 20-year-old woman & \\
\hline $\begin{array}{l}\text { wakes up, sunrise } \\
\text { prayer } \\
\text { breakfast } \\
\text { dough for bread } \\
\text { water } \\
\text { clean tandoor } \\
\text { bake nan } \\
\text { sew } \\
\text { milking } \\
\text { collecting firewood } \\
\text { tea } \\
\text { wash dishes } \\
\text { dung cake } \\
\text { washing clothes } \\
\text { fetch water } \\
\text { bed }\end{array}$ & $\begin{array}{l}\text { We don't have our own land and my husband is a farmer for others } \\
\text { but now he is sick and he cannot go to work. I make dung cakes for } \\
\text { others and I wash the clothes. When I do these, they give me a loaf of } \\
\text { bread. We don't have any kind of pots and dishes at home and I bring } \\
\text { water in } 2 \text { broken pots. We have bread and tea } 3 \text { times a day. If we } \\
\text { don't have tea, we just have boiled water. We cannot afford to buy } \\
\text { clothing, some people just give us their old clothes. I am not happy } \\
\text { with my life because of poverty. I was given } 2 \text { sheep from OXFAM } \\
\text { and I can use their milk and wool. The milk we get from the sheep is } \\
\text { good for my children. }\end{array}$ \\
\hline
\end{tabular}


While discussing their daily routines, the women frequently expressed that they feel overwhelmed with all of the demands placed on them by their husband's family, that they feel like they are treated like a maid. In times of illness or pregnancy, women's workloads rarely change, and occasionally they seek help from a female neighbor or close relative. When young brides are taken to the husband's home, they must prove themselves worthy and work long hours, relieving the mother-inlaw from the responsibility of caring for the household. Even though the women feel overwhelmed with the amount of work that is required of them, they accept this as an non-negotiable part of life as generations of women before them have done.

"I don't have anyone at home to help me, when the cock crows in the morning I get up and say my prayers and immediately start work. I work from morning until night and still nothing is done. I am happy with the life I am leading because I think I was created for this work. A few years ago, it was nicer because I had a daughter and she lent a hand with housework. Since she married a few years ago, I feel lonely. I wish I only had to do housework, I also have to work outside, such as feeding animals, milking cows, collecting firewood and doing some other work with my husband"-45-year-old housewife, Punjao

Besides maintaining the household, women play active roles in the agricultural division of labor. These activities include milking the animals, care and feeding of livestock and poultry, collecting wild grasses and medicinal plants. They share the responsibility of fodder collection, harvesting and wheat threshing with the men and children. Grazing and herding are typically the responsibilities of young children, both boys and girls.

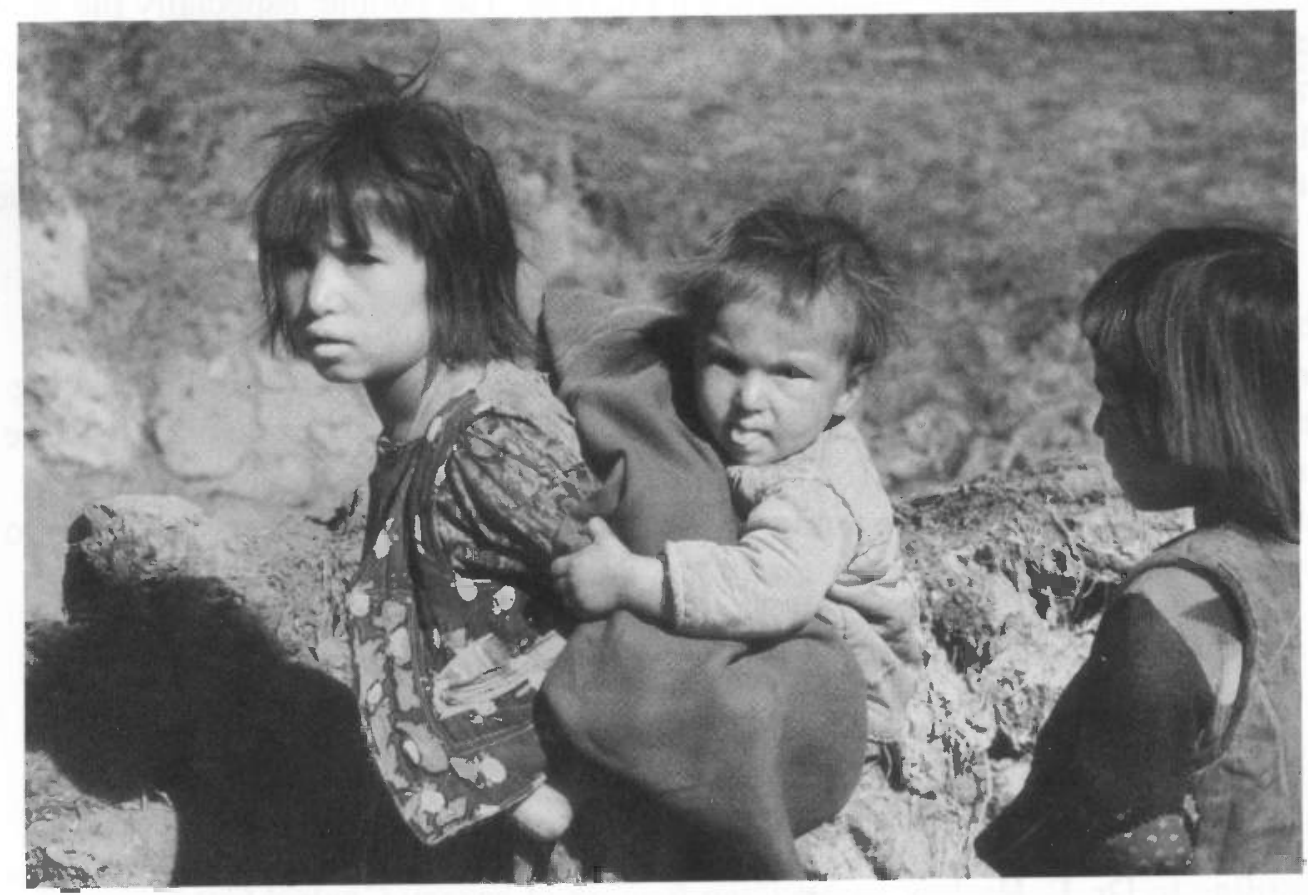

Child care activities are frequently carried out by other children. 
For the researchers, an interesting omission from the women's lists of daily activities is child care. When asked about this, women replied that they don't consider that a chore, it is just part of life. Siblings are most often charged with looking after the younger children, as well as grandparents. The observations of the team indicated that children are dirty, unkempt, and that children suffer from numerous skin infections, runny noses and coughs, and poor hygiene. Women do not have much time to devote to child care, but it is also reflects local standards of hygiene, and a definite area for intervention

\section{"I do all the housework by myself and I get tired. If I don't work at} home, my husband will beat me. He says I got married to you so you can work for us. If you don't work, go anywhere you want, I don't need you. I work like a servant. I have 5 children and I have to wash clothes every day-I don't wash clothes with soap I wash with a "wild" soap. If I get sick, I call my neighbor to help"-24-year-old housewife, Punjao.

\subsubsection{Respiratory Ailments}

The second most frequently mentioned problem is various kinds of breathing difficulties, with asthma named as the most common condition followed by breathing problems, cough, chest problems and pneumonia. Forty percent of the women complained of some kind of respiratory ailment or breathing difficulty.

"We have weakness, long-lasting cough and dizziness"-_.group discussion with women

The causes for respiratory problems are numerous. The people, especially the poor, live in crowded and poorly ventilated houses for several months on end during the winter, and the fuels they burn, mountain shrubs and cow dung cakes, produce irritating smoke. A significant cause of chest tightness/shortness of breath for women can be anemia. To some extent, goiter is a cause of difficult breathing when the enlarged thyroid gland impinges on the trachea.

Tuberculosis was identified in 3 groups in a paired ranking matrix, and was mentioned by 25 men and women in other interviews as a terrible problem facing them. It is interesting to note that when women were asked about their knowledge of sexually transmitted diseases (STDs), tuberculosis was thought to be one such disease by eight women. One young woman in Punjao described her symptoms to the team, and it is likely she has contracted TB:

"I have this swelling under my ear, the pain is unbearable, and I am losing my hearing in that ear. I am waking up at night with fever and sweating. I am weak and I do not know what is wrong"-24-year-old woman in Punjao.

According to Dr. E. Hasker, a physician from the Leprosy Control Organization (LEPCO) in Hazarajat, the annual tuberculosis risk rate is $3 \%$ for this region. The 
figure means that for every percentage point, 50 people per 100,000 per year will contract a new active case of TB. The estimated population for Yakawlang and Punjao combined is 196,120 - therefore nearly 300 new active TB cases a year will occur. Women are disproportionately affected $-70 \%$ of the active cases of TB appear in women between the ages of 15 and 50 . The reason for this has not been conclusively determined. The WHO Global Tuberculosis Program suggests that the hormonal and nutritional stresses of pregnancy might weaken a woman's immune system, increasing her susceptibility to developing TB in the post partum period.

"One of my daughters died in infancy and one when she was 18 years old due to TB"--45-year-old female in Yakawlang.

The expected outcome of this disease is that the cases remain open for approximately 2 years; $50 \%$ will die within 2 years, $25 \%$ will be spontaneously cured, and $25 \%$ will go on to develop a chronic state, which results in disability and premature death. The cumulative effect of this disease results in the deaths of hundreds of women over just a five-year period. Because of the high cost and complexity of TB treatment, MSF in Punjao refers all cases of TB to LEPCO in Yakawlang. Most people simply go without treatment.

\subsubsection{Headache}

"We are all in bad conditions. We are all the time sick, and even when we are well, we have headaches and back problems"-group discussion with women, Yakawlang.

Headache was another frequently mentioned complaint in the ranking matrices. Twenty five percent of the community groups named headache a problem. Further probing into the symptoms revealed that headaches imply other meanings for people aside from a standard biomedical description of actual head pain. Dr. Sima and Dr. Leena both confirm that headaches are often metaphorical terms for stress, worry, social pressure, and depression. The section on mental health will explore headache further in this context.

"Most of the men said (about women) that stillbirth is a dangerous thing for the women. it causes headache, problems with breathing, heart disease, etc"-from a group discussion with men, Punjao.

The PRA team did not make a distinction between somatic complaints of headache and actual pain experienced in the head. In other regions of northern Afghanistan, people use two words to imply to headache, but further study in Hazarajat is required to identify if there is an ethnomedical term that people use that makes a distinction between types of "headache". Although headache may often be a psychosomatic phenomenon, it is important to explore the presence of headache as head pain to identify organic causes of the symptom. Brucellosis, a zoonotic ${ }^{7}$

\footnotetext{
${ }^{7}$ A zoonotic disease is an infectious disease that is transmitted from vertebrate animals to humans.
} 
disease contracted from improperly boiled infected cows milk, causes a long term syndrome in which headache is a frequent symptom. Other causes for head pain include poor ventilation, anemia, eclampsia, and untreated hypertension.

\subsubsection{Goiter}

One third of the women complained of goiter and displayed evidence of goiter of various sizes. The surgeon at the Punjao hospital reported that partial thyroidectomy for treatment of goiter it is not an uncommon surgical procedure. This is performed on women who are experiencing breathing problems due to the size of the goiter, which was also confirmed by Dr. Sima. Dr. Leena noted that in spite of the significant presence of iodine deficiency, women were not giving birth to mentally retarded children. The people did not know about the association between iodine deficiency and goiter, and they cited many causes of goiter, ranging from the use of fertilizer, headache, eating too many potatoes, drinking dirty water, and eating unclean things.

"Women have goiter, and it is caused by potatoes, living in cold climate, weakness in the body"--From a group discussion with men, Punjao.

\subsubsection{Other problems}

Many non-specific complaints of stomach pain were identified. There was one mention of chronic diarrhea/dysentery by a woman who reported having blood in her stool for six months, but she could not get permission from her family to see the doctor. Dr. Leena attributed chronic parasitic infections (also contributing to what women describe as kidney pain), poor diets, and greasy food as being responsible for a large majority of stomach discomfort.

Skin problems are prevalent as reported in 5 matrices. Many cases of scabies were seen by the PRA team, as well as what appeared to be fungal infections. Children's skin often looked old and wrinkled, especially their hands and feet, which were creased with obvious layers of dirt. Women complained that they did not have access to clean water and cannot afford soap, and this was identified as the main cause of their skin problems. Some of the women adapt to the lack of soap by reverting to traditional methods of using local plants, minerals, herbs and yogurt for bathing and washing clothes. For example, 2 women reported that they use a leaf called ustook-o-usmishak which has a good scent and is used to wash clothes. They also use clay to wash their hair and body, and a local plant gum is used for the hair to give it a shine and keep it in place.

Eye problems were also mentioned, and the complaints were largely poor vision, especially at night, symptoms consistent with conjunctivitis, and eye irritation from smoke. Most women reported bleeding gums (both in adults and children) and they believe this is due to not keeping teeth properly clean, lack of toothpaste, and eating very hot and very cold food. Nosebleeds were cited by 4 groups as a frequent problem, especially while baking bread. Likely causes for this are the high altitude 
dry cold air, frequent upper respiratory infections, smoky indoor environments, and baking bread over the hot tandoor. People link nosebleeds with a spiritual affliction as well

\section{Summary}

Women named several illnesses such as musculoskeletal problems, respiratory difficulties, headache, poor vision, and goiter--all of which have causes rooted in nutritional factors, but they also produce problems in reproductive health, and compromise mental health. Micronutrient deficiencies are evident among women and children, and awareness of these disorders is highly dependent on women who have lived outside of Hazarajat. The consequences of malnutrition expose women to the risk, for example, of chronic iron deficiency anemia, as well as a contracted pelvis from vitamin $\mathrm{D}$ and calcium deficiencies, which leads to life-threatening obstetric complications. The physical environment of Hazarajat necessitates high kilocalorie requirements for optimal energy levels, and it is likely that most women are not consuming the required calories. Tuberculosis is going to remain a difficult problem to solve, as the many months - from 9 to 12 - of treatment with several drugs is difficult to monitor in these rural areas, and $\mathrm{BCG}$ vaccination is quite rare. Most of these disorders the women identified can easily be prevented with improved nutrition, water supply and basic primary health care

\subsection{Nutritional Knowledge and Practices}

"We just eat to stay alive. We don't know what is nutritious and what is not"-group discussion with women, Yakawlang.

The link between women's health and nutrition is clear from the above problems identified by the women themselves. It is evident that food shortages are not the only factors contributing to nutritional deficiencies, but local customs and food habits also play an important role

The traditional diet of region is very basic. Bread (naan) is the staple food, and it is usually a whole-wheat leavened bread baked in a sunken oven (tandoor) or on hot skillets. The dough is made by mixing the wheat or barley flour with water; occasionally a legume flour is added and/or oil. The dough is left to rise for a few hours, and is baked in the tandoor. Barley is also a staple cereal, and is used to make bread by the very poor when unable to afford wheat. Rice is quite highly valued, but because it is very expensive, it is reserved for special occasions only. Legumes, such as broad beans, chickpeas, kidney beans, mung beans, and lentils are also used when available. Legumes are most often used in soups or ground into flour to be mixed with wheat and barley flour for bread. Milk products are an essential part of the diet, and are enjoyed as yogurt, butter, cream, buttermilk ( $\operatorname{dogh})$, and a delicacy favored throughout Afghanistan, qurut, which is dried sour yogurt. Fats are consumed as ghee, as well as animal fat. Meat is overwhelmingly the preferred source of protein - and is valued by all. Mutton and beef are consumed whenever available by 
those who can afford it. Poultry is gaining in popularity, with turkey being the preferred fowl.

Vegetables are not consumed on a regular basis by the majority of households for a number of reasons. One is that all available land is dedicated to the production of staple foods, and so vegetables are given less priority. The two most common items found in a typical household garden are potatoes and tobacco--tobacco cultivation is on the rise, and is appearing in more household gardens than ever before. Tobacco is used in the form of snuff by men as well as women-in Hazarajat, it is socially acceptable for women to use snuff.

Another reason people say they do not grow vegetables is because seeds are not always available, and the quality of the soil is not considered to be favorable for vegetable production, and the short growing season is another problem. However, the most fundamental reason for lack of vegetables in the diet is that vegetables are simply not as highly regarded and valued in the local diet. It could well be that the high energy demands for working in this cold environment require large amounts of calorie-dense foods such as proteins, carbohydrates and fats; vegetables do not provide the same calorie density, energy and sustenance. Rising costs push vegetables even further down on the list of priorities. The local population traditionally includes wild grasses and plants in their diets
"We use some wild grass in spring and also dry them up to eat during winters. There are ones that grow on mountains like fuk, siege, gozeera and in deserts shorakai, sarsham, beechandak and taff. We like to eat subzi (spinach) but it is not found now. Fruits like apricot grow here but we cannot buy it because it is too expensive. Shub kor (night blindness) and bleeding gums are common and this is because we are not fit. We are poor and sick"

According to Dr. Hassanyur of OXFAM, when the NGO first entered the area eight years ago, a few vegetables were in regular use. Turnip, potato, carrot, a sweet yellow squash, and onions to some extent were eaten in the summer. However, with the exposure to vegetables from other people as well as vegetable and nutrition projects introduced over the years by OXFAM, vegetables are slowly becoming part of the Hazaras' food habits. Women named several vegetables that they are familiar with and like to use. The most frequently mentioned are carrot, onion and potato, followed by tomato, yellow squash, turnip, radish, and eggplant. Fruits include apples, apricots and melons. During the long winters, the vegetables that people use are potatoes, onions, dried apricots mulberries and tomatoes, and occasionally dried squash and eggplant. By spring, people have eaten most of their stored vegetables, but by this time wild grasses are commonly collected from the mountains and valleys. These provide valuable nutrients until other vegetables are grown. OXFAM and UNOPS both found that if the people are presented with vegetable seeds that they are familiar with, they will gladly grow them. 
The poorest women, especially in villages distant from the main towns, admit that they don't know anything about the nutritional value of vegetables and fruit, and although they enjoy eating them, they were simply not grown much in the area. Again, the distinction arises between people who have lived outside of the region and those local inhabitants who have never left. Returned refugees and internally displaced persons from urban areas are fond of vegetables, and have a basic understanding of the nutritive value of the vitamins and minerals in vegetables These women voiced many complaints about the lack of fruit and vegetables in the market, and said that if they had seeds, they would grow them.

"How many times a day do we eat???? What kind of a stupid question are you asking? You are wasting our time"-group discussion with men, Yakawlang.

\subsubsection{Micronutrient Deficiencies}

While people are familiar with diseases such as night blindness, gum bleeding, goiter and angular stomatitis (cracking in the skin at the corners of the lips), there is a general lack of understanding of their causes. Respondents were asked about the symptoms and then to identify what they think cause the illnesses.

- Causes of night blindness (shub kor), an early sign of vitamin A deficiency, are thought to include dirtiness, cold weather, lack of oil in the body, lack of oil in the eyes, smoke, drinking water from an oily pot, and bad food. Two respondents (one woman, one man) believed it to be due to lack of vitamins. One woman said that eating sheep's liver is good for night-blindness. When the population has a local name for night blindness, it is assumed that vitamin A deficiency is a problem.

"When the oil that is available in the eyes is finished, the child will suffer from night blindness. That is why we breastfeed for 2 years"group discussion with women, Yakawlang

- Gum bleeding (vitamin C deficiency) is common among both children and adults and is thought to be caused by dirty teeth, dirty food, eating very hot or very cold food, cold weather, headache and lack of toothpaste.

- Goiter was seen in one third of the women, and people believe that it is caused by eating too many potatoes, headaches and using fertilizers in the land.

- Symptoms of vitamin B deficiency were evident from the presence of angular stomatitis (cracks in the corners of the mouth which may extend to the inner side of the cheek or to the outer surface.), but people did not mention anything about it.

- Iron deficiency anemia was observed by female PRA team members in numerous women.

- Osteomalacia was identified by Dr. Leena as a significant problem caused by vitamin $\mathrm{D}$ deficiency, or calcium deficiency or both. Women made no specific association between their symptoms of bone pain and diets. 


\subsubsection{Breastfeeding}

Because infant formula is not available, infants are breastfed almost exclusively; the exception to this is when they are given herbs to clean out the intestines. Women are advised by many of their elders and old dais not to breastfeed for the first two to three days and to throw away the first milk (colostrum) because it is considered to be bad, or fermented milk. The newborn is fed oil or ghee for those days. However, the majority of women report feeding their babies within 12 hours. Trained TBAs advise feeding within 1 hour, and the average response is 5 to 12 hours. The duration of breastfeeding varies only slightly; the majority of women report that they breastfeed for an average of 2 years, and one woman reported feeding girls for 1 year, boys for 2 years. Interestingly, there appears to be a practice in favor of girls, in which many women report feeding boys for 2 years, and girls for 2 years and 2 months. The reason given for this practice is that girls need more nourishment, and one woman also credited a mullah for advocating this practice:

"We breastfeed sons for 2 years and we breastfeed daughters 2 months longer than sons because our mullahs have told us that girls are mentioned more in our book. We give the child extra food at seven months"-small group of women.

"I tell the mother not to eat anything immediately after delivery and I tell her not to breastfeed the child unless she has taken a bath. Don't give the child milk for 3 days because the first milk of the mother can cause stomach problems. In the first day we give butter to the baby and tell the mother to take her milk out and throw it away"-40-year-old $T B A$.

Paradoxically, this TBA recommends both positive and negative practices to the women- areas for intervention must acknowledge the positive practices, while teaching women to abandon the negative practices.

One woman said that because they produce children shir ba shir (one after the other), the children in actual fact cannot be breastfed for the full 2 years if she is delivering a child at one and a half year intervals. Breastfeeding during pregnancy is not considered safe for the mother, so if a woman becomes pregnant while lactating, she will stop breastfeeding if the infant is more than 6 months old. Women consistently denied changing their diets or food consumption patterns while they are breastfeeding. Women report introducing weaning foods at 6 months. These foods mainly consist of liti and halwa.

Most of the respondents denied that there are differences in feeding practices for boys and girls. A group of women in one village said that they provide more food to sons than daughters because they go to the mountains to collect firewood and daughters stay at home. A few women in the same group contradicted this and said that both are important. Three other women reported that they "save good food for their husbands, because they have to work so hard." One woman admitted that her 
husband beats her if she gives the children extra bread. Some women commented that if their children are hungry, and if there is not enough food to feed her husband who worked hard all day, the women and older siblings would be more likely to give up their share.

Food taboos exist for certain people at certain times. For example, children are not fed eggs because of the belief that eggs cause children to become mute. This belief is by no means confined to the Hazara, as it is a widespread folk belief in Central and South Asia. Children are not fed milk because it is thought to cause kidney stones. Traditional medicine of the area is humoral, where foods are assigned hot or cold properties, to be taken or avoided depending on the type of illness. This often means that some valuable nutritious foods are avoided during pregnancy, such as halwa, but again, it truly depends on the education of the women, and/or the exposure to outside practices.

\section{Summary}

Food habits are slowly changing as people are becoming more receptive to dietary innovations. The ubiquity of micronutrient deficiencies, (iron, iodine, vitamins A \& $\mathrm{C}$, and to some extent $\mathrm{B}$ complexes in the case of the very poor who cannot afford sufficient wheat,) place the entire population, but especially children under the age of five years, and women of childbearing age, at risk for lowered immunity to infectious disease, complications associated with pregnancy and general ill health. Reducing micronutrient deficiencies must take priority in reducing morbidity and mortality among women and children.

\subsection{Care-seeking behavior}

Even when health care may be available, the first resort to care for a woman is her mother-in-law. The control over a woman's health care is usually not her own choice; there are many family pressures that constrain her ability to seek care, including her relationship with her husbands family, income, as well as accessibility to care. The mother-in-law may not allow her to go to a health care practitioner, and her husband is unlikely to disagree with his mother in these matters.

\footnotetext{
"Because of transportation problem, we have to get permission from our husbands because it is a long way from hospital. Our mother-inlaw's are forbidding us to go to hospital. They say, "don't go to a doctor, you may get well anyway" small group discussion with 4 young women, Yakawlang.
}

The townspeople living in Nayak and Punjao have easier access to modern health care, and will take the ailing person to the doctor if the family can afford it. However, even if a hospital or clinic is available, the selection of healer largely depends on the type of illness, whether it is perceived to be a spiritual or physical illness. The spiritual illnesses that are brought on by jinn and evil eyes are treated by the mullah, and the family of the ailing person will also perform a vow at a shrine. 
Other health care resources in the village include: the local herbalist (usually a woman), the chemist, a palm reader/fortune teller, and sometimes a village health worker is available who has been trained to give injections. The last resort is the hospital. One group talked about a "quack" who charges too much money in their village and gives all injections with the same syringe.

The chemist, if there is one, is commonly sought to recommend medications and treatments. A community health worker is occasionally a source of medical advice and care, and they are often referred to as "doctor", for a person with even a small amount of training is referred to as doctor. Eight women and men from several villages referred to "one man" in the village who gives injections, and he uses the same syringe for each person. It is not clear who these people are or what training they have, but it is clear that they are practising unsafe medicine.

When treating either their own or their families' illnesses women usually observe a sequential resort to care. This means that women begin with home remedies, observe for effect, and then move to a higher level of care. Many local herbs are used-these medicines, while effective in relieving many symptoms, often fail to produce a cure and people then seek a higher level of care. OXFAM is promoting the local herbal medicinal tradition that is practised mainly by women. They are working to keep the knowledge alive, and to codify the therapeutics in order to systematize the knowledge. In the fall of 1998, women herbalists taught younger women the medicinal value of local plants in a training session in Punjao.

"We have never been looked after in this village. No matter how severely ill we are we still don't go to the doctor because the doctor is far from the village and sometimes if we have a serious problems we go to a palmist who tells us what to do and tells us what our sickness is. Sometimes they tell us that our sickness is caused by fears hallucinations, and they tell us what to eat and not eat"--from group discussion with women, Punjao.

The most common traditional home remedies that women reported are:

- Boiling flour, water, sugar and ghee into a thin porridge-like consistency, and feeding the soup to the child who has diarrhea (liti). This is also given to post partum women as a strengthening and healing food

- Ashes are used to treat eye problems

- Taking yoghurt for treatment of abdominal pain or applying to skin and hair for external problems

- An herbal seed called juni badiyan is ground and mixed with a small amt. of milk, water, or hidden in candy is commonly taken for stomach problems such as gas and diarrhea

- For pneumonia, ghee is rubbed onto the chest and covered with a warm cloth

- use of opium and garam daru (medicines with "hot" properties) for difficult breathing and pneumonia

- Sheep liver is taken for night blindness 
- Placing naswar (snuff) in the nostrils for women to sneeze to release nazala (sinusitis); also for delivering placenta

- Placing spider webs in the nose to stop nosebleeding

- Placing an old shoe in the shalwar to stop post-partum bleeding

- For high fever, the patient is wrapped in an animal skin which causes excessive perspiration

Maintaining traditions of herbal medicine and home remedies is critical to the success of basic health care interventions, since many of the remedies are sound therapies and should not be discouraged. For example, liti, is a fine example of a home remedy completely appropriate for any oral rehydration need, as the ingredients are all readily available, inexpensive and familiar to the palate. It replicates "wheat-salt solution", an oral rehydration therapy recognized by WHO and other health organizations in preference to ORS. The use of sheep's liver for vitamin A deficiency must also be more strongly encouraged. Other traditions must be discouraged, particularly wrapping a febrile person in animal skins, and ashes used for eye problems. OXFAM's research on herbal medicines will provide much needed information on local healing plants and indigenous healing practices.

\subsection{Reproductive health}

"I am 30 years old and I have been married for 13 years... I was born and raised in this village. My husband is 40, and illiterate. What's more, he is jobless he is one of those unfortunate men. Other than house chores, I have nothing to do to support my family. There are 9 members in our house-4 sons, 3 daughters, my husband and myself. I have been pregnant 8 times and all of my deliveries were successful and my children are alive. There has been a space of 2 years between each child. My last child is weak and thin. My last delivery happened 8 months ago. I have never been anywhere to "take care of me" and I cannot go to Nayak because it is too far. We cannot go anywhere without permission from our husbands or elders in the family if we go out, we will have quarrels afterward. My present pregnancy looks very normal because I don't feel any kind of pain. I have some burning with urination but I never tried to get treatment. Whatever we can find, we eat it. I don't eat any special foods, and if I get something special, I give it to my children. I don't want to have any more children because I am very poor and I cannot take care of them. I have never used anything to delay or prevent pregnancy"-_Pregnant 30-year-old woman, Yakawlang.

"When we are pregnant, we cannot say that we are sick, it is not in our tradition".-from a group discussion with pregnant women, Yakawlang.

Childbearing is perhaps the most important role for women in this society, and both women and men are aware of and fear the risks that this role carries for them. One woman said that even though children are desired, women often fear pregnancy 
because it might end their lives. The male PRA team members wrote the following summary from a group discussion with men about the problems of women:

"They said that childbearing is the major problem for the mothers because they don't have any doctors and the women are suffering from bleeding. Also, while they are delivering the baby, there is kind of sudden death for the women. Bleeding after giving birth is the major cause of death for the mothers. The other problem is giving birth to a child every year. They say about this, we know of a kind of injection that delays the childbirth. Asked if he ever used this, he replied that he has used it but the others said that they don't know anything about it because it was available in Iran"

For a better understanding of reproductive health practices, the information collected was analyzed for the following major points: early childbearing and fertility; antenatal care; delivery practices and emergency obstetrics; maternal deaths; gynecological problems; family planning; and awareness of sexually transmitted diseases.

\subsubsection{Early childbearing and fertility}

Lifeline analyses provided useful information for determining the age at which women had their first pregnancy (see Annex 3). Forty-two lifelines indicated that the most common age at marriage was 15 followed by 18 , and the youngest reported marriage was 11 . More women reported having their first child at 15 years of age, followed by 18 and 20. It is not unusual for women to have a pregnancy every 1.5 years, with an average of 8 pregnancies, and three reported having had 12 pregnancies in their lifetime. Fertility is a paramount concern for every woman, and individual interviews identified several women who appeared to be having fertility problems. Three married women had no pregnancies, seven women said they had one pregnancy and had tried for more, and 3 reported frequent miscarriages

"There are 5 people in family, me, my husband and 3 daughters. I have been pregnant 12 times and I have only 3 children alive. 2 of my children died-one died after delivery and the other was 3 years old. The others were all miscarried and why they all miscarried, I don't know. All of my deliveries occurred at home. I was taken care of by a dai "...35-year-old female, Yakawlang

"...Getting married was my second happiness because now I thought I would have my own house and own life. We always hoped that I would get pregnant and have children and it never happened. Even though I went to the doctor, I still never had children. My husband died due to an illness / when she was 25\%. He was a good husband, and he never threatened to a take a second wife even though I was childless. After he died, I left and went to the home of my brother and he took me to Iran. I had an operation in Iran, the doctors took my womb out. Now I am 
alone. I have never had any happiness in my life"-- 50-year-old female, Punjao.

The causes of infertility for women in this region are many, but the most common cause is reproductive tract infections due to poor hygiene, lowered immunity because of nutritional status, and post-partum infections. Dr. M.A. Halimi, the SCUS PRA team leader also suggests that, according to his research in Kabul, tuberculosis infection of the reproductive tract may be a contributing factor in infertility. Given the prevalence of TB in women, this could be a possible explanation for some cases of infertility.

\subsubsection{Antenatal care}

Professional antenatal care is uncommon -women assume that their pregnancy is normal if they feel the baby moving, and the attitude women take is to trust in God to watch over them. Pregnant women go to shrines to get an amulet in order to have a safe pregnancy. They tie these amulets to their clothes, arms and sometimes abdomen.

Four women reported having received tetanus toxoid vaccine, and three of these were from Iran. Most women said they don't know what it means to have special care when they are pregnant. Women deny changing their diets or increasing food intake while pregnant, and their work burdens rarely change during pregnancy. Interestingly, symptoms of toxemia other than headache were not mentioned.

Traditional methods of watching pregnancies are practised, which consists of consulting dais to check the position of the baby, to get a light massage on the abdomen, and to get some advice on diet during pregnancy. A 40-year-old dai said:

"I didn't have any training to become a dai, I learned it by heart. In the last month I assisted 2 women with deliveries. The pregnant women come to me when their children are out of position and I put the baby in the right position-I just move it with my hand. I am not paid for this"

The folk knowledge passed down through generations advise pregnant women against taking "hot food" during pregnancy and "cold food" during labor. Hot foods are given for labor and are thought to put the woman at risk for miscarriage if taken during pregnancy. Dogh (buttermilk) is considered to be a cold food and is thought to hinder the delivery process, but it is a safe food during pregnancy. Hot foods to be avoided during pregnancy are eggs, chicken, and halwa. Dais claim to be able to determine the position of the child, and then to put the baby in proper position with their hands by rubbing the outside of the woman's stomach.

\subsubsection{Delivery practices}

"I got pregnant only once and my son died $1 / 2 \mathrm{hr}$. after delivery. I was 20 when I delivered my first child. My child died because a dai took me on 
her back and shook me. I wanted my delivery to happen at my father's house because I had my mother there and she could help me. The dai was not trained. During delivery I didn't use any kind of medicine. When my child was born, the dai cut my baby's cord but did not tie it because it was not alive. The placenta was delivered normally. For 40 days, I had severe bleeding, fever and bad breath and I went to the doctor. Now I suffer from burning dysuria, backache, headache"-30year-old female, Yakawlang.

Without exception, all deliveries take place at home, unless there is a severe complication, and then the woman endures a long trip by horse, donkey or cart to the hospital if possible. Dr. Sima reported that it is a common practice for a young woman to have her first child at her parent's home so she can be attended by her mother. Births are usually assisted by the mother- or sister-in-law, or other close relative only; this is because of the fear of the "evil eye" from women outside of the clan. The evil eye is considered to be the most common cause of death for women during childbirth, as it is for stillbirth and infant deaths.

Some elder women of the village are regarded as dais, although most of them have had no formal training. Some trained TBAs, and occasionally husbands or young daughters will assist. Women who assisted with births ranged from women who were trained in a formal program to women who had no training whatsoever, and by virtue of their experience, age and inclination, functioned as dais. Women reported that they do not go to the dais because they are not skilled and therefore do not trust them. Some women said that their husbands and mothers-in-law refused to let them go to dais because of "people's gossip" and the danger of evil eye.

One male dai was found in Punjao; he is 30 years old and his mother was a dai, and said:
"I have always lived here since I was born. I work in construction and I have a little land. I have studied up to grade 12. My mother was a dai. I read a book called "Where there is no doctor". I have assisted 12 mothers since last year. I checked my wife when she was pregnant to make sure that the baby was in the right position. I can put them into the right position. I put my hands on the mother's abdomen and press the womb. I also do this when women suffer from pain. When the child is born I cut the cord and tie it with clean string. I tell the mother to sleep, and I put a cloth on her to keep her warm. If the mother has a lot of bleeding I advise her to take vitamin $K$ and I encourage the mother to breastfeed the child as soon as possible. I suggest that after delivery mothers should take light food, they should not eat rice and they should avoid lassi and other sour foods"

Because of the importance of warmth during delivery, women reported that they give birth in the tandoor khana [baking room], or in a stable. The woman is usually placed on a woolen namat [thick woolen felt] or old toshak [floor mattress] covered 
with dirty rags. Most women and their assistants do not observe clean techniques for hygiene and cord cutting practices. There were no women or TBAs interviewed who reported placing substances on the umbilical cord of the baby to help healing.

Traditional belief systems around childbirth guide the practices of women. There is a belief that the baby needs to be separated from the womb, and various methods to achieve this are used:

“... When I assist with a birth, I don't wash my hands because they just get dirty. I have no instruments, and I get a blade and string from the family to cut the umbilical cord and tie it. When the mother is giving birth, I give her some hot milk with ghee or hot water in order to keep the mother warm so that the child can separate from the womb. If the mother gives birth to twins or is she is suffering from problems, I give her a glass bottle to blow in to separate the children from the womb, or I give her some snuff to make the mother sneeze. If this doesn't work, we call someone to fire a gun to scare the mother, and then automatically, the children are separated from the womb"-50-year-old dai.

A few dais reported physical means of separating the child from the womb where the laboring mother is subjected to the following ordeals:

"First, I put the child in the right position and assist the woman to give birth. I beat the back of the mother with the palm of my hand to help the mother give birth easily. I wrap the mother's feet so that they can get warm. If the mother doesn't give birth. I lay her over my back and bounce her. I don't use any equipment. My equipment is God who helps me"

One more story from a 56-year-old dai is difficult to imagine:

"First I check the position of the baby and help put it into proper position. Then I place the woman in a blanket and swing her Iback and forth in the blanket] - this helps separate the baby from the womb. Then, with the woman sitting on floor, I take the woman's hands and push down on her stomach with my foot. I give the mother warm milk with ghee or oil; this lubricates the birth canal and the skin of the child. If woman delivers, I advise the mother to wait 12 hours before feeding the baby. I immediately cut the cord with whatever is available and tie it. I put the mother's end of the cord under the heel of her foot, and leave a hand's width on the child's side. The mouth of the child is filled with oil. The placenta should come out. If it doesn't, I place snuff in her nose which causes sneezing, or, I secretly ask someone to go outside to fire a gun to scare her so it [the placenta] will come out"

Snuff is commonly placed in the nose to make the woman sneeze during birth and for delivery of the placenta. Dais use scare tactics to facilitate delivery of placenta. 
If the gun blast is unsuccessful, one TBA finds it useful to frighten the mother by asking someone to go out and find dog feces to bring to the dai so that she can feed it to the mother. She reports that the woman is so upset when she hears the threat that the placenta will come out.

Dais are not skilled at detecting early warning signs of obstetric complications, and when the labor reaches a life-threatening situation, it is often already too late. TBA training projects sponsored by Oxfam and MSF in Punjao have had a positive impact on birthing practices in the region. TBAs who participated in these programs practise hygienic birthing practices and conscientious cord care. A maternal-child health clinic in Punjao operated by MSF promotes antenatal care and provides tetanus vaccination. A 50 -year-old dai who was trained by a physician in Yakawlang reports that she uses the following practices.

"I have assisted 3 women giving birth. When they have pain, they come to me. If the child is mispositioned, I put the child back into the right position. Sometimes they give me money, sometimes they give me a ring, sometimes they give me wheat. When I check the woman's stomach and when I see that delivery is not close I tell them to go back home, but if the delivery is close, I lay the woman down, and I tell her when she feels severe pain to tell me. When she tells me that she is suffering terribly, I wrap her feet and stomach. I wash my hands with hot water. I have a pair of scissors, clean string and forceps. These were given to me by Dr. Ali. I boil all these things, make the bed for the mother and tell the woman to keep herself warm in order to prevent bleeding. I tell the mother to eat good food and especially mustard oil. After the baby is born, I tie the umbilical cord and then I cut it with the scissors, and then I tell the mother to wash her breasts clean with hot water and soap and then breastfeed the baby because the first milk of the mother gives strength to the child"

Very little information was obtained about post natal care practices, and it is not clear from the information given how long (if at all) the woman recuperates from childbirth, or delays sexual intercourse. The accepted Islamic practice requires that the woman recovers for 40 days before resuming intercourse. Most likely, the poorest woman has little opportunity to rest and recover from childbirth, and must resume her work within a day.

\subsubsection{Maternal deaths}

Men and women both report concerns over too-frequent deaths of women from childbirth-related causes-during the interviews, twelve women were reported to have died from childbirth-related causes in the previous year. Most of the causes are cited as retention of placenta, bleeding, obstructed labor, and fever. From the information provided from interviews with relatives and neighbors of women who died, many women died several weeks after delivery, but determining the exact cause is impossible from the information provided. 
An indirect measurement of maternal mortality indicates that of forty-two lifelines, $17(40 \%)$ of the respondents stated that their mothers died before the respondents reached the age of 12 , the average age was 5 . The devastating effects of maternal deaths was described by family members, especially when women described the loss of their mothers at a young age. The respondents described a life of privation and hardship and confided that their stepmothers often did not accept them as their own. The girls especially often depicted the stepmother as cruel, treating them like servants.

"My mother died while delivering. Then there was no-one to take care of us. At that time my sister was 8 and I was 5. We suffered terribly and we didn't have clothing and food and most of the nights we went to sleep without eating. My father worked very hard, but sill we had problems. When I was 10 my brother bought me a new dress and I was very happy because for the first time, I had a new dress. My father said that we will sell everything in the house and move to Iran. I was very happy to hear this"-12-year-old girl, Yakawlang.

\subsubsection{Gynecological problems}

Women spoke freely about their conditions to the interviewers, but rarely have the liberty to verbalize their difficulties to family members. Women cited vaginal bleeding as the most frequent problem followed by uterine prolapse, pain after delivery, vaginal itching, vaginal discharge, back ache, and burning dysuria [burning with urination]. Back pain was also mentioned frequently, but in this area women engage in heavy manual labor throughout their lives, during pregnancy and shortly after delivery. This is a contributing factor to both back pain and uterine prolapse. It is difficult to draw any conclusions about reproductive tract infections from the data, however, given the frequency of bleeding problems, unhygienic childbirth, complaints of pain and fever after delivery, and unhygienic living conditions, RTIs cannot be ruled out as a problem of concern. Women shy away from getting treatment, because they are often too embarrassed to explain the problem to their husband or his family.

"We have vaginal prolapse, backache, problems with kidneys. Such kinds of diseases are seen very much in this village but we cannot discuss our problems with anyone because it is very shameful"--group discussion with women, Punjao.

\subsubsection{Family planning}

"I don't want too many (pregnancies) because I am so weak, but it is not in my hands. People coming from Iran must have brought tablets with them because they don't get pregnant too often. If someone has such pills to give me, I would love it"-26-year-old pregnant woman. 
The majority of women are not using contraception, and they do not know about contraceptive methods. Some women say that it is the decision of the husband whether or not to have children, others say that many children are a blessing, and still others feel that it is God's will, that it is their destiny to bear many children. However, there was much interest in spacing births because the women complained that they are weakened from frequent childbirth, and because of poverty, families cannot afford to feed and clothe too many children. Men also commented that women are growing weak from having a pregnancy every year. Older women who have many children are particularly interested in contraception and are eager to learn more about it. Some have heard rumors from other women in the village that there is "anti-pregnancy" medication, especially from the women who lived in Iran, Kabul, or Ghazni. Women say that their husbands brought "capsules" and tablets from the bazaar for them to use, but they didn't work.

"I used a kind of capsule which I bought from a woman in the village but it didn't work. I don't know why. I want to have gaps between my deliveries. If you have something to prevent such problems, please give us to solve our problems"--group discussion with women, Yakawlang.

Pregnant and recently delivered women were asked if their pregnancies were wanted. Twelve women confided that their pregnancies were not desired, citing health reasons and poverty.

"... When my son was born, I was very happy, but with the second son, my husband said you have nothing to do except for delivering children. He said don't have any more children because I cannot afford to take care of them"-23-year-old female, Yakawlang.

Abortions were not discussed at all, and only one woman alluded to induced abortion:

"I have three children living and there is three to four years gap among them. When I come to know that I am pregnant, I adopt a "traditional method" to stop the child from coming"'--no age given.

According to Dr. Sima, abortion is not commonplace, but it does occur. The two traditional methods of terminating a pregnancy she is aware of in the area include (1) taking an overdose of quinine, and (2) inserting a piece of bark into the cervix. The bark absorbs moisture from the surrounding tissue, the cervix dilates, and the woman loses the pregnancy. Dr. Leena indicated that interest in family planning is a new phenomenon in this region. She suspects that it may be due to the growing level of poverty, as well as exposure to people from other regions who have used these methods. Men as well as women are looking for ways to space births, and were very interested in learning about contraceptives. UNOPS male community liaison officers also confirmed that men were asking about family planning methods, and that they would support a family planning project 
"With the permission of my husband, I will use the pills. My husband brings them to me but still while taking the pills I get pregnant. I don't know of any other method. If there is any other way, just tell me!"-group discussion with women, Yakawlang.

Important to the people's acceptance of contraception is the fact that the Iranian clergy have encouraged family planning as acceptible to the Shia faith, as is evident from some Shia-dominated areas of northern Pakistan

\subsubsection{STD awareness}

Very few women had any knowledge about STDs. Tuberculosis was most frequently identified as being transmitted by sexual contact. Other frequent responses of diseases transmitted sexually were flu, typhoid, toothache, diarrhea and dysentery. Perhaps they understood the question to pertain to any close physical contact between women and men as opposed to genital contact only. All men and women deny the existence of "illegal sexual activity" in their villages and HIV was unheard of.

"In our area there is no sign of such disease. They don't have the habit of having sex with other people because they are busy all the time, but in Iran people used to suffer from burning urination which I think is caused by illegal sexual relations" - small group discussion with men, Yakawlang.

\section{Summary}

As women and men both named maternal deaths as their gravest concern, interventions should target all aspects of reproductive health. Maternal mortality is influenced by many factors, but for the women in Bamyan, maternal deaths are related to numerous factors including:

- High frequency of pregnancies

- Age of mother at first delivery

- General health of mother

- Lack of education for women

- Lack of autonomy in decision making

- Inadequate awareness of antenatal and postnatal care

- Unhygienic and unsafe delivery practices by TBAs
- Inability of TBAs to detect early signs of complications

- Absence of referral system for obstetric emergencies

- Inability to afford health care

- Limited access to health care and contraception

Any woman who is pregnant can develop complications at any time, and the lack of prompt, adequate emergency obstetric services will keep maternal mortality high. However, basic primary health care interventions can play an important role in improving women's overall health that will reduce the likelihood of developing lifethreatening complications. Improving the health care infrastructure will require 
years of planning, capacity building, and resources that are not easy to come by for this area. Maternal mortality and morbidity cause much stress and anxiety for the entire population, in addition to the other factors such as poverty, isolation and war. The next section will examine the issues around mental health.

\subsection{Mental Health}

Exploring an indigenous understanding of mental health with this population yielded some interesting results. Described below is an attempt at understanding the Hazaras' perceptions of mental health, and the way mental problems are defined at the individual and group level. Women's mental health issues were most successfully explored through an indirect approach, and information obtained in tools such as lifelines, livelihood analyses, and daily routine diaries. These tools, rather than direct questions about mental health, provide very clear indicators as to the levels of stress and how the women are coping with their problems, illnesses, children's deaths, poverty, and political insecurity.

When direct questions were asked about mental health and mental problems were posed by the PRA team, it appears that mental health connotes a more concrete interpretation of mental illness, that is, whether one is "insane" or "crazy." What is clear is that the PRA team did not clarify what they meant by mental illness/health, however the respondents seemed to make distinctions between mental health and profound mental illness that generally results in bizarre behavior. Both men and women reported that there are a few "mad or crazy" people. These cases were clearly recognized and the families take care of the person as best they can. For example, one man spoke of his brother who shouts at people and tries to hit them; and another woman "who beats herself a lot and she quarrels about nothing" (widow in Punjao). Others said there were no mental problems. One man (in a group discussion in Yakawlang) noted that "our village has a good climate so you can hardly see any kind of disease there. There are no mental diseases, we don't have any crazy in our village."

As for the mental health/well-being of women, this must be viewed in the context of the current situation. Some of the factors that were identified by women were:

- protracted strife and political instability

- the effects of isolation and growing sense of vulnerability and helplessness due to hostilities and the blockade

- infant and child mortality

- economic conditions, poverty and hunger

- gender relations and women's decision-making

It also became clear that research on mental health in the context of this society must not overlook two very important aspects of life in their specific cultural context: spiritual/folk beliefs and women's social status. Belief in supernatural events concerning good or evil omens and spirits around birth, death, sickness and marriage are firmly established in local traditions, and are often used as outlets for expression of otherwise socially unacceptable feelings. Gender relations and 
women's social status have a profound impact on women's self-perception, decision-making, and coping mechanisms to meet their many demands. Women identified a few stress-related illnesses, and headaches are an especially good example.

4.6.1 Jinn Possession as mental health indicator and female social protest expression

The belief systems around forms of spiritual sicknesses from dangerous entities are well-accepted causes of illness and death. One such syndrome the people refer to is jinn-jinns are spirits or genies who possess the person and force them to do unusual things. Respondents in all districts freely discussed jinn with the PRA team, and it is well-known malady among both women and men who identify it as a form of spiritual decline. When someone is possessed by these jinns, she will act according to the nature of the jinn. A good jinn will recite verses of the Quran through the mouth of the possessed person, even though she has never had any training in doing so. ${ }^{8} \mathrm{~A}$ bad jinn makes the possessed perform bizarre acts, like setting fire, breaking kitchenware, removing their clothes, or falling into a catatonic trance. The treatment for jinn is to go to the shrine and perform a vow, and see a mullah who can exorcise the jinn. Most people believe that there is no medication to treat jinn because it is a spiritual illness, and left untreated, it can cause death. Descriptions of jinn include:

$\begin{array}{lll}\text { foaming at the mouth } & \text { nervous tics } & \text { talking to oneself } \\ \text { falling unconscious or fainting } & \text { nosebleeds } & \begin{array}{l}\text { removing clothes } \\ \text { during a possession }\end{array} \\ \text { having too much fear } & \text { seizures } & \text { hallucinations } \\ \text { nervousness } & \text { biting the tongue } & \end{array}$

"When a woman is frightened they faint and they undress themselves. Then we take the woman to the shrine and we hold the woman tightly in a place inside the shrine"-30-year-old female, Punjao.

"Mental illnesses are jinn and headache-when people have this they are considered to have mental problems. Depression is also considered to be part of mental illness and this is seen a lot in our village. People who are suffering from these things are called cowards and pitiful people and mostly women suffer from such diseases"-male, no age given, Punjao.

The people who participated in the PRA perceive jinn possession as being on the rise. From a mental health perspective, jinn possession for women is an important

\footnotetext{
${ }^{8}$ Poladi, H. The Hazaras, p. 150
} 
outlet to express their emotions in a socially acceptable manner. Cultural norms of female behavior can be broken without threat of punishment when under the spell of jinns. Women and men have no other way of expressing their stress, frustrations and depression other than escaping into jinns, and while some people see it as a weakness, it is accepted that the person is not acting voluntarily, it is the jinn acting When they come under the control of jinn, the unusual behaviors are dealt with, the person is kept safe, and the patient is taken to the mullah and to a shrine where a vow is performed for the afflicted. For women, jinns are the only way to call attention to themselves and their emotional distresses

It is clear from the above descriptions of jinn that dangerous and fatal illnesses are also caused by jinn, such as tetanus, and other illnesses that produce tetany such as febrile seizures, meningitis, encephalitis, and epilepsy. This has important implications for health education, because spiritual beliefs must be considered in interventions

"People have jinn, and 4 of my grandsons have died from this. Such kinds of incidents are very common. I have another grandson and I am worried about this happening to him too"-65-year-old man, Yakawlang.

"Mental problems? They faint, foam at the mouth and bite their tongues, If they are outside, they try to put themselves in the water before it happens. It is difficult to treat such problems in Yakawlang"-male, no age given.

Another supernatural belief that is particularly risky for women and children is the "evil eye." Women who are close to giving birth, newborns and infants are particularly susceptible to the evil eye which is believed to be caused from a gaze of a jealous person or spirit, and can result in death. As was mentioned in the reproductive health section, women from outside the family are not usually permitted to attend a birth because of the evil eye. This makes TBA training a very important planning issue.

"In our village there is only one woman who suffers from mental disease. In the summer, they tie the woman up in order to stop her from teasing people. But in the winter she gets better. She is looked after by her relatives and family". 40-year-old male from Yakawlang.

\subsubsection{Local descriptions of emotional distress}

Others noted that mental illness is on the rise due to the grim living conditions, poverty and war. Community members clearly identified that depression was a problem in their village and they had no cure for it.

"Depression is one of the sicknesses that cannot be treated"-male, no age given, from Punjao. 
"We are vulnerable and miserable people"-group discussion with women in Yakawlang.

In Mata Dar-e-Nargis, some women feel that poverty has caused a lot of depression in the area and that there is no medicine for depression. One woman clearly stated that depression is mental illness and that it has increased in the area. Most people attribute depression to the severe poverty of the region, illnesses, frequent deaths of loved ones and to the continuing war and blockade. Here is the story of a 14-yearold girl in Yakawlang:
"I lost my mother when I was only 5 years old and I lived with my father and brothers who loved me very much. When I was 6 years old my father went to Kabul and got lost there and never returned. I do not know whether he is living or not. During this time my best sister also died due to a complicated delivery leaving behind my niece who I love very much and take care of. When I remember all these sad incidences I cry a lot and faint and later feel pain in my whole body. I have never seen happiness or at least I do not remember any happy moments. Maybe Allah has created me to suffer for the rest of my life"

Both child and maternal mortality are devastating to the entire family, and especially so for the young daughters who are left behind. With persistent undernutrition combined with early and frequent pregnancies, infant mortality rates are often high. In 42 lifeline analyses, 38 women gave birth to 141 children of whom 73 died $(52 \%)$. Most of these deaths occurred in the first year of life due to pneumonia, diarrhea and measles. Women, in particular, listed deaths in their kinship circle as a key factor in their level of suffering. In community mental health terms, these factors must be taken into consideration in order to address the mental health of women; program development in the region that reduces morbidity/mortality rates will have a direct impact on depression and anxiety.

Many women were heard to comment during the interviews that they "prefer death to this life", "I pray for God to take my life", "I have never seen happiness", and many more allusions to hardship, suffering and depression. Despite the readiness to express these emotions, and the tendency for women as well as men to say that they prefer death to this life, there were no reports of suicide. From this PRA, it is not possible to assess whether suicide is occurring, or on the rise, and moreover, it is not likely that people would report it because Islamic tenets are strongly opposed to suicide.

The women in the study, as well as the men, spoke of generalized weakness, bone pain, and body aches. Because "bone pain" was often described as generalized pain rather than joint pain, this indicates a likelihood of somatic reaction to stress and depression. This would be consistent with findings in the refugee camps and with studies of Afghan refugees resettled in the Pakistan and the United States. Weakness could be a state of health based on the poor diet and hard work, but it is a common category or condition identified by women to describe themselves. It also used to 
describe a feeling of fatigue or general thinness of body. As with the complaint of bone pain, weakness can be an indicator of stress and depression, but because of its nonspecific use by women to describe themselves, it is not predictive of mental health status.

Another very common illness noted for both health and mental health is that of "pressure" which must not be mistaken for high blood pressure. The term is used to describe anxiety and is also described as pressure rising to the head, and also causes headaches. Many noted its existence and some men reported that the war in Afghanistan, poverty and their inability to provide for their families has caused preshaany and that preshaany has made a lot of people ill and a few have gone crazy

Finally, some people noted that many are suffering from headaches and illnesses that they call asaaby. Participants said that war and poverty have made people asaaby. This also refers to worry, nervousness and anxiety due to stress. The term refers to "nerves" and indicates that the people of this region perceive a connection between stress and its effects on the nervous system, as do others in Afghanistan. Some women are known to pass out or faint, and it is not always related to jinns.

"Fear causes a lot of mental disease for women and they go unconscious and the husbands take them to the shrine or hospital"-_50year-old male, Punjao.

Going unconscious, or "falling out" from extreme emotional distress is a wellknown phenomenon in the region. UNOPS female community liaison officers, on a routine visit to a village in Yakawlang, came across a woman who had been unconscious for 2 days. Her family was very concerned, and the woman was taken to the hospital in Nayak, started on an intravenous drip, and was given an injection. She was awake and well the next day. Doctors at the hospital say that they see this problem on a regular basis: women go unconscious, are brought to the hospital and are routinely given a placebo injection and they are better by the following day. This pattern of behavior represents a culturally accepted method of coping with grief, depression and stress

\section{Summary}

The stress of living in poverty, the real possibility of food shortages, the inferior status of women, and fear of outside attack and retribution by the Taliban contribute to women's risks of mental illness in many forms. Information solicited by the PRA team about mental illness suggests that the team may have approached the subject in such a straightforward manner that when participants were asked about mental illness, they may have interpreted the interviewers' questions as pertaining to chronic/profound mental illness. Another possibility is that the interviewers' own cultural biases toward mental health entered the interviews and reporting. This is important to bear in mind for future training programs, with the lesson learned to train health care workers to make a distinction between treating mental illnesses as 
opposed to promoting mental health. Nevertheless, community mental health issues were naturally explored in the interviews because the topics pertained to things very personal for the women. The women were also unaccustomed to outsiders taking an interest in their lives, experiences and opinions. This would more than likely account for the outpouring of emotions when women described their circumstances. The most emotive responses came out when the women discussed the loss of children, family members, and matters related to gender equality and social status of women.

\subsection{Gender Issues and Attitudes Toward Women and Girls}

At the time of this research, women were not living under Taliban rule, and gender relations were representative of traditional rural Hazara society. Comparatively speaking, Hazara women are more visible and mobile than women elsewhere in Afghanistan; also, the practice of female seclusion (purdah), is not strictly enforced, as the rural lifestyle necessitates active involvement for both genders division of labor. In order to court the UN and NGOs, leaders of Hizb-e-Wahdat took pride in emphasizing the fact that women were not subject to the extreme policies of the Taliban, and that they respected women's role in society. They voiced a commitment to women's rights, and did not interfere in programming targeted for women. Now that the Taliban have won control of the region, no one is sure whether or how this will change women's roles in society.

The following topics were analyzed for their relevance to women's health: decision making; women's mobility; marriage patterns; preference for sons; polygamy and the co-wife; and domestic violence.

\subsubsection{Decision Making}

The following quotes indicate gender ideology pertaining to decision, however, a brief PRA such as this one is unlikely to reveal subtle nuances about day to day realities which may challenge and resist such notions.

"Some women have the rights to make decisions at home but most of us don't allow them to do this. Without our permission they cannot go anywhere or do anything. In general, women must get permission when they want to go anywhere, like to hospital, or her father's house. When girls reach the age of 12 they are not allowed to leave the house" - 40year-old male, Yakawlang.

Women and men both explained that women are not free to make decisions by themselves, nor are their opinions and views often sought in the decision-making process. Some men say that only when women contribute to the household income can they make decisions; others say that if the woman is literate, she can participate in decision-making. There are conflicting opinions on what kind of decisions women should be permitted to make, for instance, should she be able to decide whether or not to go to a funeral or visit her father's home? Some men are less 
restrictive than others in their opinions on this matter. Women appear to be resigned to this lack of input in matters that affect their lives.

"No-one has ever told us that women have any right to decision-making and women should not be free to do as they please"-group of men, Yakawlang.

Women are visible on the streets and roads, working outside in the fields, and walking unaccompanied by other male family members, however, the bazaar continues to be the social space of men, and women are rarely seen in the marketplace. This implies notions of gendered spaces which need to be explored further in this population. Women and men readily acknowledge that women are free to go anywhere they want in the village, but they must get permission from her family, or from her husband's family if she wants to leave the village. There are subtle variations in this requirement in individual cases, where some families and husbands are stricter than others. If they want to see someone outside of the family, for instance, visiting a doctor, a dai, a palmist, or to visit a shrine, permission must be obtained-sometimes it is not granted because the woman cannot take time from her work at home, or due to fears of the husband's family that people will gossip if the woman is seen socializing. The quotes from men clearly impart their sentiments and customs with respect to women's decision-making ability:

"Anyhow, men are the only people who can make decisions. Women are all the time sick, and when they are sick they cannot think about anything. Therefore, men have the most authority in every respect of life"-40-year-old male.

"Women don't have the right to make decisions. Women in our village are illiterate and know nothing"-male, no age given.

"Women have the authority to make decisions and that they are free. They can do any legitimate actions. They can go to the funeral, and they are free to do so"-50-year-old male.

The above quotes indicate men's views on the rightful place of women in society. It is obvious that men would not want to indicate publicly what could easily be construed as "powerlessness" in relation to their women. But a young married woman expresses what she thinks the rights of women:

"In my area, women who don't have husbands are luckiest of all because they can make decisions like what to eat, what to wear"-15year-old female, Yakawlang.

"We have the right to eat and work. We don't even have the right to talk. They don't let us talk to anyone"-female in Punjao, no age given. 
As in other muslim rural societies, rights, freedom and mobility depend on women's stage in the life cycle. Women who have enjoyed a less restrictive existence in other regions find their status changed since moving back to Afghanistan:

"I was very happy as a child because I was living with my family and I didn't have to think about anything. When I was 15 I got married and it was a happy period in my life. When I was 20, I had a son, because I had a son, I was very happy. I don't like daughters because we have a lot of enemies in our village and I am worried about taking care of a girl. When we were in Iran we were participating in juma prayers and we were free to go wherever we wanted. When we came to Afghanistan we lost that independence, and I am very sad"-25-year-old woman, Yakawlang

It is interesting to note that they were allowed to go to the mosque in Iran but not in Afghanistan. Although the Hazara practise Shia Islam, the way this is interpreted in Iran and Hazarajat varies considerably. Despite the acceptance of the culturally proscribed decision-making rights of women, they still acknowledge the emotional effects of their powerlessness, particularly when it comes to the time of marriage.

\subsubsection{Marriage Patterns}

"My mother suffered from bleeding and there was no-one to take her to the hospital and now I am depressed because everyone my age has their mother but I don't. I have my father and brothers but they don't take the place of my mother. My father is remarried now and doesn't care about us. If we asked him for anything he beat us. When I became older, I was married but I don't like my husband because he is not a good man. He is a gambler. Now that I am in my husband's house I am not happy. When my uncle died I was 10 years old and I can remember only one thing from my uncle - he was always telling me to get married according to my wish. I made fun of him saying such things, but now I agree with him"-25-year-old female, Punjao.

Marriage matches are the domains of the parents who control the choice of spouses for their daughters and sons. Girls are usually between the ages of 13 and 18, the average age is 15 when they are married. Many women report that fathers are forcibly selling their daughters for large sums of money (brideprice). The brideprice was not specified in the interviews, and in many cases it is land or livestock. There are some substantial differences between the perceptions of men and women around the issue of marriage. More men commented that marriages are not "compulsory", and that the girl is very often consulted in the choice of the boy for marriage, and that girls should be at least 14 . One man commented that girls should be 19 at marriage. Women did not have that perception, and at least half the women who provided lifelines reported their marriage as a being a sad event because of their youth, inexperience, and the selection of the husband by parents. 
"There are lots of compulsory marriages in our village and it happened to me as well. I didn't like my husband at all--neither his face nor his character but I had to because it was my father's choice"--interview with a woman, age not given.

Several families cannot afford to arrange a marriage for their sons because they don't have enough resources to pay the brideprice. One man reported having to work for his future father-in-law for several years before he was permitted to marry the man's daughter.

"Women have no rights because their fathers sell them and take money from us"-40-year-old male, Punjao.

Marriage patterns differ among socioeconomic groups, and some women observed that age at marriage is lower because of poverty. Families are anxious to lessen the burden of feeding and clothing many children, and they also need the brideprice in these difficult economic times.

"Women get married normally when they reach 14 and there are some people who get married when they are 11 or 12 and the cause of such marriages is poverty and in the last few years, this has been seen very much"-24-year-old male, Yakawlang.

The commodification of girls is yet another factor in the feelings of helplessness that contribute to a woman's depression. Clearly, many women expressed satisfaction with their marriages, but just as many women identified their marriage as a sad event because of the selection of the man by the parents.

"All my childhood was spent in poverty and sadness. I was working as a shepherd from the time I was 5. I had only one brother who was also a shepherd. When I was 14 I was forcibly married to a 70-year-old man. My father got a cow and a piece of land for me as a brideprice. My husband is an old and weak man. At the beginning he treated me badly, and he beat me and told me "you have to work instead of me". I had to collect firewood, work as a shepherd and even plow. Even now I carry my I-year-old daughter on my back (while I work). If I don't, I will be beaten 5 times. The only happiness in my life has been having 2 children. I was hoping that having 2 children would change my husband's behavior, but it didn't work"-25-year-old female, Yakawlang.

"All the marriages are arranged according to the parents' will, and boys and girls don't make the decision. When the girls reach the age of 12 or 13, they are married because when a girl reaches puberty it is a sin to keep them at home"-individual interview with a 35-year-old woman. 


\subsubsection{Preference for Sons}

"I was very young when my father died and I had to shoulder all the responsibility in the family. I was happy to be married because I thought I could have my own life and the girl was my favorite and we had a good life. I was sad with the birth of my daughter - girls are very weak and cannot defend themselves. They have to go to another's house, and they are beaten. A son is a good thing, they can fend for themselves and if the son is good he supports the parents"-44-year-old male, Yakawlang.

In this agrarian society, sons are highly valued as economic assets that carry a guarantee of security for the family, while daughters are regarded as burdens. The birth of a daughter is a highly stressful event for a woman who endures tremendous pressure to bear sons. The more daughters that are born, the more vulnerable the wife is to abuse by her husband and his family, and ultimately, she is more likely to experience the husband's marriage to a second wife which is almost always a very painful turn of events. Women do enjoy having daughters because they are seen as helpers and companions for the mother, but only after she has borne sons. Some women expressed great sadness about the birth of daughters, because they say that women endure such suffering they fear that their daughter will have the same difficult life that they do. Hearing women express grief at the birth of a daughter is a tragedy. It is tragic because the woman is persecuted for an event over which she has no control, and because she feels guilty for bringing a child in to the world to suffer as much as she does. Women related many stories that revealed what bearing daughters means to their lives:

"I was very happy to have sons because they have a future, but the girls, they don't have a future. When I gave birth to my daughters, I was reminded of my bad times" -25-year-old female, Punjao.

"When I got married I was very happy because I married my cousin and I loved him. At that time, my husband's family was very good to me up to the time I got pregnant. When I delivered a daughter they were sad and they started to treat me differently. They started to fight with me and they don't care about the daughter and they say that girls are useless. After 2 years I got pregnant and again I had a daughter. Their sadness and depression increased. When I was pregnant they didn't help me at all and I had to do all the housework. My third child was also a girl. When this happened, they started becoming very cruel to me and they told me that I had to clean the stable. It was hard work. One day when I was cleaning the stable and taking the waste out, it was very heavy, I had [uterine] prolapse. Now I have dizziness and headache but my husband doesn't care about me. He won't take me to the hospital. But I went to a palmist and he told me that I will never have any more children. My husband fights with me all the time and tells me he will marry a second wife"-30-year-old female, Yakawlang. 
While daughters are undervalued by the family as a whole, women are relieved when they have at least one daughter so that they can not only help with household work, but also take care of her younger brothers and sisters. This is not to say that daughters are not loved by the family, or that they are rejected. Many women recalled their childhoods in their father's home as the happiest time of their lives. As Poladi writes, "The daughter is loved and cherished. She is supposed to be the custodian of the family honor and prestige. She is expected not to bring any bad name or shame to the family. And she is the one who shoulders the responsibility of managing the household if the mother dies."
"I was very happy with my marriage because I had seen my husband and I liked him. I was very happy with my first delivery because I became a mother and I had a good and happy life with my husband. I was sad with my second delivery because it was a girl and my husband and his family were not happy. When I had a third daughter, my life became very difficult with his family. Finally, my husband decided to get married again to have sons, and I became a maid. The most difficult thing is that my husband died when I was 32. I don't have an income. Some of the people in the village help me. If they didn't my children would starve. I don't have a good life, and I am not happy with it"-32- year-old woman, Punjao.

\subsubsection{Domestic Violence}

Women bluntly reported that beatings are common occurrences, and it was not confined to husbands, fathers, and brothers; women confided that stepmothers were frequent perpetrators of abuse. Mothers-in-law were not often implicated in physical abuse, but cruelty was a common complaint, and it is not clear from some of the interviews whether cruelty implied physical abuse as well as psychological abuse. Both men and women explain that when a woman disobeys her husband or his family, or fails to get permission to go out, beatings are justified. Child abuse was mentioned, and is often related to children growing up with stepparents and relatives. Whether or not domestic violence occurs more frequently here than in most societies is not clear from this study. However, poverty is a well-known intensifier of violence, and thus may be part of the pattern that is being observed.

"In our area, women are beaten a lot whenever they don't accept what their husbands say, then that is the time to be beaten"-Group discussion with women, Yakawlang.

"I wasn't happy when I got married because I didn't like the man and I had to get married because my parents said they wanted to see me married before they died. When my son was born, I was very happy, but with the second son, my husband said, "You have nothing to do except for delivering children." He said, "Don't have any more children because I can 't afford to take care of them", and he beats his sons and he beats me too. He says that ever since I have come to his home, he has 
not seen any happiness. My teeth are loose because of the sorrow and grief I have. Once, I was baking nan in the tandoor khana and my husband came in and tried to put my head in the tandoor"-23-year-old female, Punjao.

"If I go somewhere I get permission from my mother-in-law or husband. If I don't they will beat me and I have been beaten 2 times. The first time, after my son fell off the donkey and it was my fault, my husband. beat me. The second time, when I took his tea to him late, he beat me"20 -year-old pregnant female, Yakawlang.

Violence in any form will inevitably have psychological impacts such as those mentioned in the section on mental health. Fear and shame, hysterical fits and outbursts may occur as well as depressive illness.

\subsubsection{Polygamy and the co-wife}

"Up to the time before my daughter died, we had no sadness, but when she died, we became very depressed because she was a lovely girl. When my husband married a second time, it was the worst time in my life and all the happiness drained away because I didn't do anything wrong to my husband, why did he get married a second time? In fact, my husband is the cause of all my sadness, and now he lives with his second wife, and this is the fourth day that we don't have anything to eat. I don't have any skills. He won't divorce me"--40-year-old female, Yakawlang.

Only six women discussed polygamy, a practice common to the region, but it is not clear how frequently it occurs. They reported that their husbands have taken second wives for various reasons, most frequently because the woman does not bear the man a son or any children. When women are widowed, the brother of the dead husband is obliged to marry his widow, thus providing security for the family of the deceased. Two women were in such an arrangement, but in one case, the brother is much younger than the widow, and the woman has been abandoned by her brotherin-law who has a young wife and a new family to provide for. One woman said that her husband took a second wife because it was a "love marriage." For the first wife, a second wife is seen as a threat, and as the PRA revealed, women are often relegated to the status of a maid. At this time, prevailing economic conditions are more than likely suppressing the tradition of polygamy.

"I was very sad when I got married because it was compulsory. I cried a lot but it didn't work. At that time I was very young and I didn't know anything. When I had my first son, I thought my husband would stop beating me. When my second son was born, I was very happy and thought that they would take care of me. I was always praying for a daughter to help me. But when I was 25 my husband took a $2^{\text {nd }}$ wife, and it was a love marriage. We lived in the same house, and we fought all the time. Then when I was 35 years old he kicked me out of the house, 
saying that I was useless. I went to my brother's house, and now I have TB. I have 2 sisters-in-low and they don't like me"-58-year-old female, Yakawlang.

"I've never ever seen any happiness in my life. When I was a child I had a stepmother [father took a second wife when she was 12] who was very cruel and used to beat us a lot. My brothers were very young. My stepmother was cruel to my mother. My mother had to work day and night, and when she came home no one would even offer her a cup of tea. When she came home, we were not allowed to giver her tea or bread but my father's behavior toward her was good. When I was 16, my father arranged my marriage with a man who was all ready married and since I went to my husband's house I haven't seen a day of happiness. My co-wife is very cruel to me and now I suffer the same things that my mother was suffering. When I was in my father's house my stepbrother used to beat me with a stick and rope. Now at 50 [years old], still my husband beats me. Last year my husband beat me with a piece of iron and I had to go to the hospital. I prefer death to this life" 50-year-old woman, Punjao

\section{Summary}

Women's inferior status has obvious implications for their mental, as well as physical health. Although women rarely challenge the patriarchal authority, they nevertheless suffer in silent indignation at being treated as second-class citizens, as their comments imply. The sense of powerlessness, feeling exploited as a young wife in her husband's home, enduring socially sanctioned beatings, and exhaustion from long days of work predispose women to anxiety, loss of self-esteem and depression. While there may be forms of female resistance that were not identified in this study, a more in-depth study of gender issues may access this information. The manifestations of these emotions, discussed in the previous section on mental health, such as fainting or suffering from jinn possessions, are the only options women have of expressing their distress and depression. Women's social isolation is further compounded by discrimination from other female family members who perpetuate gender inequality as part of longstanding cultural tradition.

Unlike so many regions in contemporary Afghanistan, accessibility to women is not a problem in this cultural context, as women enjoy relatively free mobility, however, women do not have control over resources, and are not in the position to make decisions for herself as well as for her family, which has important implications for health seeking behavior. Domestic violence was reported as a common occurrence. However, from the information gathered, it is not evident whether sexual violence is a problem in this population. Girls experience an abbreviated adolescence as they marry at early ages and are uninformed about their sexual roles and responsibilities as young married women. Girls grow up with the knowledge that sons are more highly valued than daughters, and gain their status by bearing sons. At this time, there is little understanding of women's social networks, 
methods of social support and other means of coping. More research will be required to plan effective interventions that aim to improve women's mental health in terms of social support interventions. 


\section{Conclusions and Recommendations}

"All the area is under the spell of evil spirits and poverty. I wish there was an amulet or magic that can get the evils out of this place so that our lives can become happy again"-70-year-old woman, Yakawlang.

In summary, pressing health care needs for women are evident from this study. In the absence of a well-developed primary health care referral system, immediate interventions will necessarily have to take the form of aggressive health education and small-scale projects until the health care infrastructure can be developed. Focus group research and in-depth interviews are required to reach a fuller understanding of nutritional habits, ethnomedical terminology, and traditional medicine for a comprehensive understanding of local attitudes and areas for intervention. The people are eager for assistance, they are open to outside intervention, and the taskat-hand is to now apply what we know about women's health needs to concrete actions.

The information gathered in the PRA will be summarized, and recommendations for planning interventions and areas for further research and/or planning interventions will be made. It is obvious that the health care needs for women in these districts are comprehensive, and the problems identified in each section must be viewed holistically, for as the model below implies, all of the problems are highly interrelated.

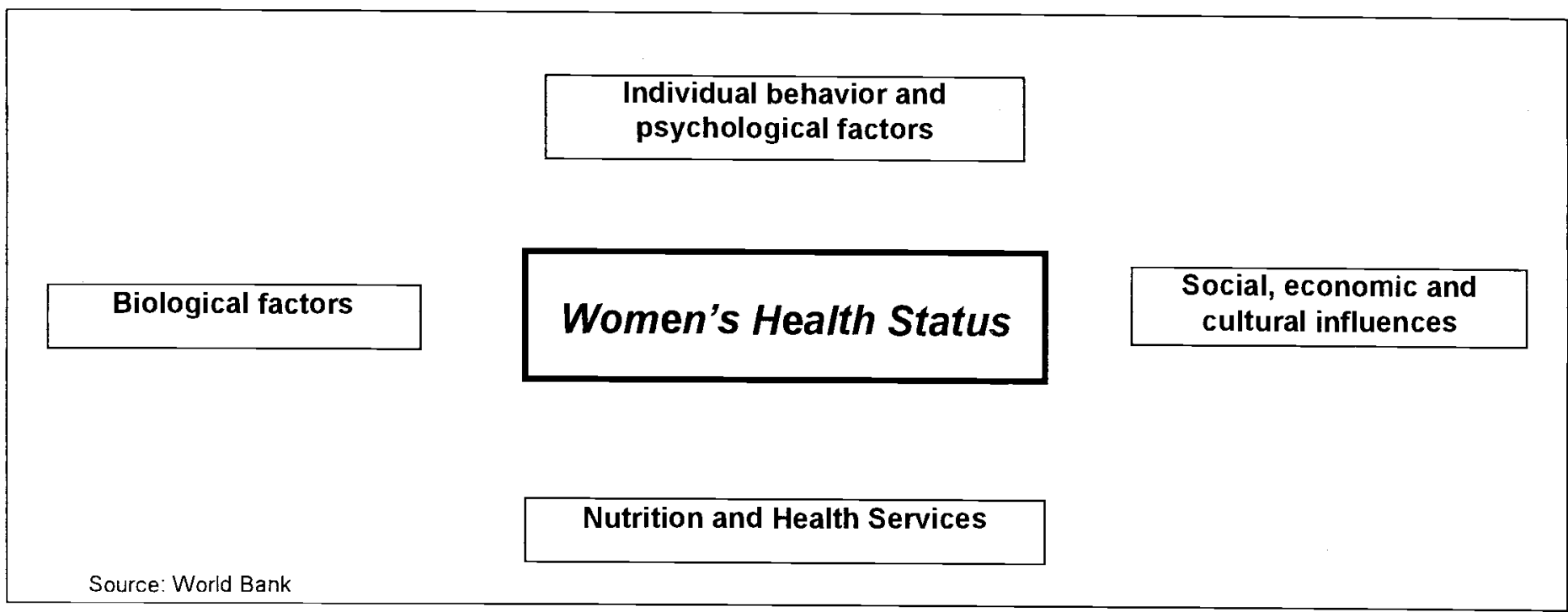

Social, economic, and cultural circumstances modify health and nutrition practices which in turn influence individual behavior and psychological factors. Many of the methods that would be effective in addressing the illnesses and problems identified by the women are fundamentally based in poverty alleviation, disease prevention and health services provision in addition to female education and women's empowerment. A comprehensive primary health care programme is required to meet 
the needs of the people here, but that requires years of planning and implementation as well as a steady investment of resources. While there may be goodwill on the part of the people to correct their problems, in the present political circumstances there is little governmental support available to initiate sustainable and positive change Therefore, it is incumbent upon UNOPS to initiate efficient and equitable subproject activities that will have the greatest impact on health of the population with very limited resources.

Planning health sector interventions must take into account a myriad of constraints and problems. The infrastructure required to implement needed community-based health care is under-developed, or completely lacking. Health care services are not accessible for the villages distant from the town center - this requires that the possibility of mobile health care teams be considered for delivering essential services. Local human resource capacity is a significant problem, which therefore necessitates a strong emphasis on training and capacity building. Seasonality is a major planning consideration for two main reasons: long months of winter restrict activities and require a separate planning strategy, while the summer months pose other problems. In the summer, when the region is more accessible and project implementation is possible, at least one-third of the population moves from the villages to the mountains - this is an important factor for health projects that promote immunization, health education as well as nutrition education that targets women, particularly for promoting vegetable gardens. Now that the Taliban have entered Bamyan, programming might be affected if the strict laws governing women's participation in development are applied to the women of this region

The Shuhada Organization is re-opening the hospital in Nayak, which will provide a foundation from which to develop collaborative health sector activities. For example, the hospital compound has the space to grow a demonstration household garden to promote the use of vegetables in the diet and to provide nutrition education for women who attend the clinic. UNOPS will continue to fund and expand the Community Health Training Project with Shuhada all ready in existence. UNOPS is in a position to support Shuhada in seeking additional funding for further health sector activities with other UN agencies, particularly UNFPA, WHO and UNICEF, who may be able to assist with reproductive health, vaccination and vitamin supplementation campaigns, and essential drug programs.

The most sensible approach to women's health in this region is to concentrate on the most essential interventions which focus on reproductive health, health education that works to promote positive practices and eliminate harmful ones. These interventions must be based within a selective primary health care framework. The most pressing needs that have been identified in this PRA that UNOPS can assist with are:

1. Nutrition interventions

2. Increased food production in women's domains, such as sustainable vegetable production, increased poultry production

3. Reproductive health care, including pregnancy services and family planning 
4. Health education

5. Support for water supply and sanitation infrastructure

6. Women's education and empowerment, bearing in mind the following points for women's programming considerations:

- Gender issues are culturally constructed and based in the power relations between men and women. Understanding the position of women informs programmatic efforts to design effective interventions that do not place any woman at risk for punishment and violence

- All projects that target women should be designed in ways that are consistent with the cultural norms, for example, understanding the need for women to gain permission from their husbands and elders must be acknowledged. Because women here are not the principal decision makers, men and family members should be included in women's health interventions

\subsection{Nutritional Knowledge and Practice}

A large proportion of the main causes of women's ill-health and maternal morbidity and mortality are directly or indirectly linked to nutrition. Pre-pregnancy weight, pregnancy weight gain and iron status are critical indicators of pregnancy outcomes Years of nutritional neglect beginning at an early age perpetuate a cycle of malnutrition and poor health that passes on from generation to generation:

- malnourished at birth

- growth stunting

- pregnancy during adolescence

- underfed and overworked during pregnancy and lactation

This leads to the following cycle:

\section{Intergenerational cycle of growth failure}

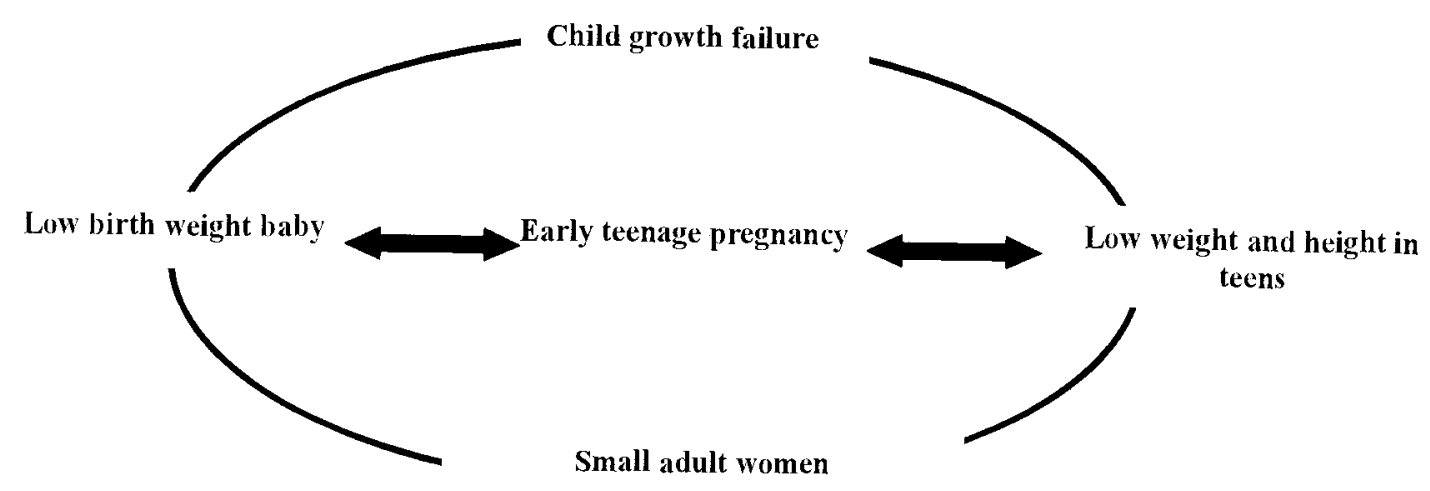

Source: ACC/SCN, 2nd Report on the World Nutrition Situation: Vol. 1: Global and Regional Results, ACC/SCN, Geneva, 1992 
Recommendations to interrupt the cycle of growth failure that leads to women's health problems are the following:

- Nutrition training, with high priority given to improving nutritional intake of young and adolescent girls, and promotion of locally available foods that are withheld due to folk practices and beliefs

- Encourage the use of household vegetable gardens, to promote vegetables in the diet and hands-on nutrition training, vegetable preparation and storage techniques

- Integrate nutrition topics in non-formal education curricula for women

- Emphasize the need for immunizations for children and women of childbearing age

- Address micronutrient deficiencies through supplementation campaigns coupled with immunization

- Further research on nutritional knowledge and practices is needed to identify positive nutritional practices and build on these

\subsection{Increase Food Production}

- Working in cooperation with FAO Crops and FAO Vets, integrated programming could include collaboration on income-generating activities for women such as sustainable vegetable production, poultry production and improving technology for wool spinning

\subsection{Reproductive Health}

Women need access to a broad range of reproductive health services in addition to birth control.

Reproductive health must address these areas: safe motherhood practices with particular emphasis on hygienic birthing practices, TBA training with emphasis on nutrition, detection and management of obstetric complications, and meeting the expressed desire for contraceptives.

The underlying causes of maternal morbidity and mortality include

- High frequencies of pregnancies from adolescence

- Limited access to health care, long distances and inadequate transportation, and absence of referral systems for obstetric emergencies

- Untrained TBAs who practice unsafe and unhygienic delivery practices, and who cannot detect or manage complications

- Inferior status of women

- Nutritional deficiencies

Recommendations for interventions in Reproductive Health:

- $\quad$ TBA training

TBA training must take into consideration that it may be more effective if at least two women from every village or extended family receive training. TBAs should 
know how to provide basic preventive and hygienic care, and to detect early warning signs of complications. Training should also include post-partum care to detect infection.

- Midwife/Lady Health Visitor training

Following the Lady Health Visitor paradigm that has been successful in Pakistan, the midwives would be trained to a higher technical level. They are more astute in identifying and managing obstetric complications, can provide family planning services, and health education.

- Antenatal care

Antenatal care is required to help detect and manage some pregnancy-related complications, such as toxemia or infection, as well as to educate women about danger signs, potential complications, and where to seek appropriate help. It is also an opportunity to teach preventive care that will benefit the infant as well as the mother, such as counseling on immediate breastfeeding, hygiene and nutrition. Specific interventions include:

- Tetanus immunization

- Screening for high blood pressure to detect toxemia

- Iron supplementation

- Iodine supplementation

- Safe Delivery

- Safe management of routing deliveries under hygienic conditions

- Detection, management and referral of obstetric complications

- Work to improve referral system

- Postpartum Care

Training TBAs to monitor for infection and hemorrhage.

- Family Planning

The community must be involved in family planning initiatives, as any successful contraceptive program depends on the cooperation of the man as well as the woman.

\subsection{Community Health Education}

Reaching remote and widely scattered villages for broad-based community health education will be required to train the community health educators to perform the following functions:

- promote hygiene

- promote nutrition

- promote basic sanitation

- promote immunization

- provide education on prevalent health problems such as diarrheal disease, skin diseases, respiratory tract infections

- provide appropriate treatment for common diseases and injuries 
- Male community health workers should educate men on the importance of supporting women to receive antenatal care and to practice safe birth techniques

- Safe motherhood initiatives must be promoted in the community through social mobilization campaigns with the assistance of community health workers

\subsection{Support for Water Supply and Sanitation}

Further investigation is required for a more complete understanding of water and sanitation-related behaviors.

- Training the population on locally available appropriate technology for water purification, i.e. sand filters and solar irradiation

- Explore various methods of water supply, such as hand pumps, shallow wells, spring water protection, and piping spring water

\subsection{Gender Issues}

- Ongoing dialogue with community organizations (Shuras) is important to garner support for health interventions that target women

- Further investigation is required to determine feasibility of developing women's social support networks

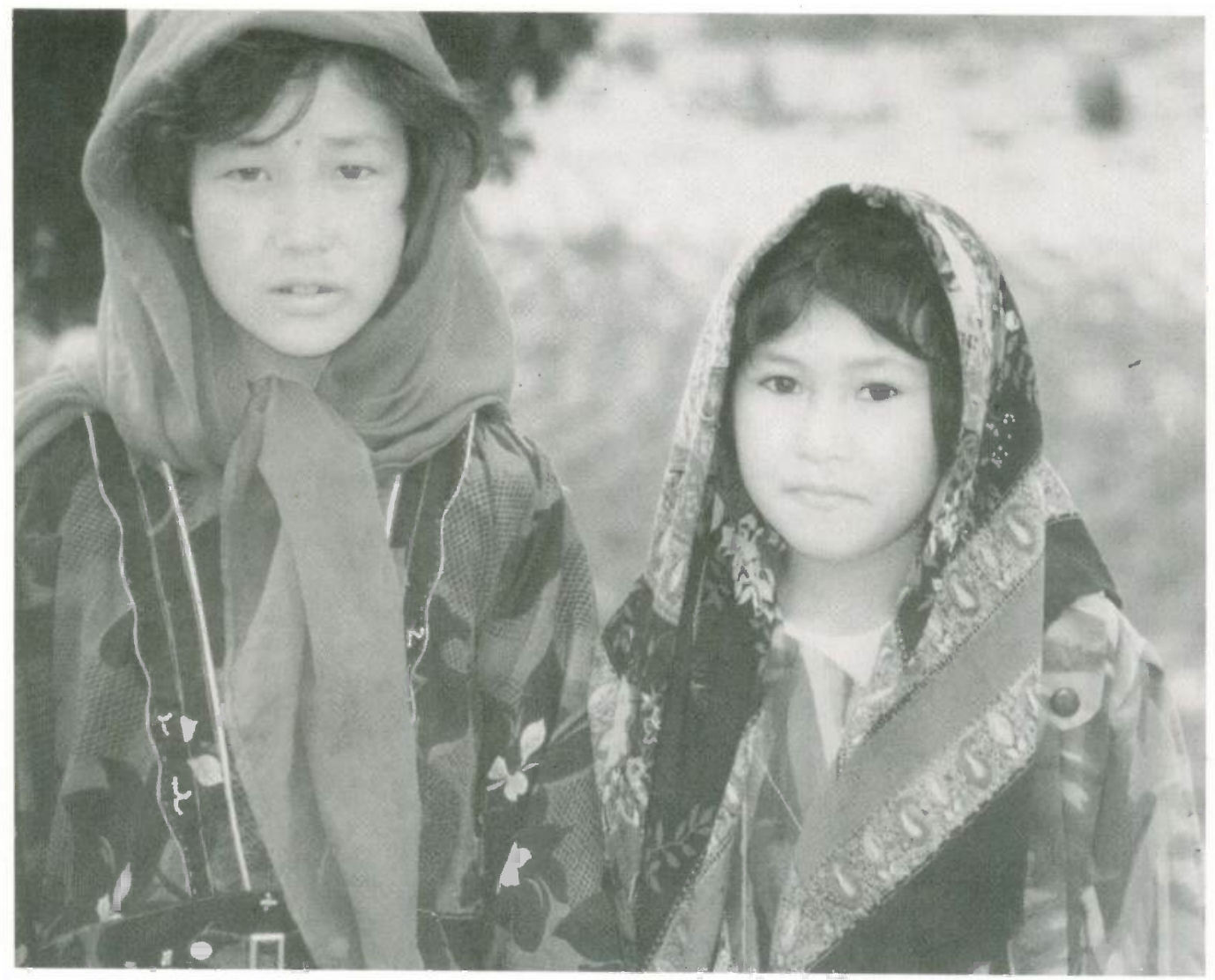

Young girls in Bamyan face many challenges in the future 


\section{References}

ACC/SCN. 1992. Second report on the world nutrition situation: Vol. 1: global and regional results. Geneva: $\mathrm{ACC} / \mathrm{SCN}$.

United Nations Afghanistan. 1991. Bamyan Province: a socio-economic profile. UNIDATA: UNDP/OPS \& UNQCA.

Eade, D. and Williams, S. 1995. The Oxfam handbook of development and relief, Vols. 1 \& 2. UK and Ireland: Oxfam.

Poladi, Hassan. 1989. The Hazaras. Stockton, California: Mughal Publishing Co.

Tinker, Anne et al. 1994. Women's health and nutrition: making a difference. The World Bank: Discussion paper no. 256.

Mousavi, S. A. 1998. The Hazaras of Afghanistan: An historical, cultural, economic and political study. Surrey: Curzon Press. 


\section{Annex 1 Checklist: Women's Health key issues}

\section{General problems and health concerns}

1. General community's problems and needs

- What are the main problems in the community and what are some of the ways people can solve them? What problems can they not solve?

2. General health status and health problems for women and children

- How would you rate your overall health, good, fair or poor?

- What are some of the problems that women have keeping healthy?

- What are some of the most common illnesses women suffer from in this village?

- What are the health problems that take lives of women? What is the most common cause of death?

- Do you have any illness right now, and if so, what is it, and have you been seen by a health care provider? For example, TB, goiter, high BP, anemia, hepatitis, kidney problems, skin problems, eye problems, stomach problems, joint problems, headaches).

3. Health Care Services

- Is health care available?

- Who are the health care practitioners?

- Where are the HCPs ?

- Where do you go to get health care: for treatment of women; for treatment of children; for delivery; for emergency obstetric care?

- How far must you travel, how long is the wait when you do go to the doctor?

- How much of your time is spent seeking health care? Does this prevent you from seeking health care?

- Do you have to get permission to see a health care practitioner?

- Do you pay for health care?

- How much of your income is spent on health care?

- In your opinion, how can health care be improved in your community?

4. Availability of medications

- Are drugs available?

- Are they affordable?

- Where do you purchase drugs?

- Do the dispensaries have a steady supply of drugs?

- What drugs do you most commonly use?

- What do you do if you need medications and you cannot afford them?

5. Identification of vulnerable groups

- Who are the most vulnerable groups in the area? (in other words, who is the worst off?)

- How do these vulnerable groups earn their living?

- How do they address health problems and meet health needs?

- Does the community help them, and they do, how?

- Can the group help to locate on a map where vulnerable groups are?

6. Education

- Are there schools in the area? 
- Are the schools for boys and girls?

- What is the highest education level?

- Where do people go for further education?

- What do people think about education? Especially for girls.

- What are the educational needs in the community?

- What are the main problems providing education?

7. Livelihood analysis

- What are primary sources of income and main income activities?

- What are women's income generation activities?

- How are household expenditures distributed? Specifically look into the portion of money spent on health, education, animals, food purchasing and production, and clothing.

- What are women's decision making power in household spending?

- Are expenditures for social services (health, education) spent in public or private sectors.

- Are children involved in income generation?

8. Women's nutritional knowledge and practices

- Is there enough food to feed your family? If not, what is not available?

- How many meals a day do you normally eat? Ask what they ate last evening.

- What does a typical meal consist of?

- Do boys and girls eat the same foods?

- Do girls eat at the same time that boys and men do?

- How does your diet change during pregnancy?

- How long do you breastfeed your baby?

- What causes goiter, night blindness, weakness, swollen/bleeding gums?

- What kinds of vegetables are available? What kinds of vegetables do you like to include in your diet? What fruits?

- Do you grow vegetables for your own use?

- How are vegetables regarded by the women - are they considered to be important to health?

- What food taboos exist for women and children?

9. Reproductive Health

- Assessment of women's background characteristics

- Pregnancy history

- Antenatal care practices

- History of delivery practices

- Post-natal care

- Emergency obstetrics

- Maternal mortality

- Birth attendants, including TBAs and daias

- Family planning

- Other reproductive health problems 


\section{Annex 2 Examples of paired-wise ranking matrices}

\section{Community Problems}

\begin{tabular}{|l|l|l|l|l|l|l|l|}
\hline & poverty & illiteracy & health & $\begin{array}{l}\text { unemploy- } \\
\text { ment }\end{array}$ & flood & No. & Rank \\
\hline poverty & & poverty & poverty & $\begin{array}{l}\text { unemploy- } \\
\text { ment }\end{array}$ & poverty & 3 & 1 \\
\hline illiteracy & & health & $\begin{array}{l}\text { unemploy- } \\
\text { ment }\end{array}$ & illiteracy & 1 & 2 \\
\hline health & & health & health & 3 & 1 \\
\hline unemployment & & & $\begin{array}{l}\text { unemploy- } \\
\text { ment }\end{array}$ & 3 & 1 \\
\hline flood & & & & 0 & 3 \\
\hline
\end{tabular}

\begin{tabular}{|l|l|l|l|l|l|l|l|}
\hline & Health & $\begin{array}{l}\text { Unemploy- } \\
\text { ment }\end{array}$ & Poverty & School & Drinking Water & No. & Rank \\
\hline Health & & health & poverty & poverty & poverty & 1 & 3 \\
\hline Unemployment & & poverty & unemployment & unemployment & 2 & 2 \\
\hline Poverty & & & poverty & poverty & 6 & 1 \\
\hline School & & & & school & 1 & 3 \\
\hline water & & & & & 0 & 4 \\
\hline
\end{tabular}

\begin{tabular}{|c|c|c|c|c|c|c|c|}
\hline & Poverty & Illiteracy & Clean Water & Unemployment & Health & No & Rank \\
\hline Poverty & & Poverty & Poverty & Poverty & Health & 3 & 2 \\
\hline Illiteracy & & & $\begin{array}{l}\text { illiteracy/ } \\
\text { C. water }\end{array}$ & $\begin{array}{l}\text { unemployment/ } \\
\text { illiteracy }\end{array}$ & health & 2 & 3 \\
\hline C. Water & & & & clean water & $\begin{array}{l}\text { health / } \\
\text { clean water }\end{array}$ & 3 & 2 \\
\hline $\begin{array}{l}\text { Unemploy- } \\
\text { ment }\end{array}$ & & & & & health & 1 & 4 \\
\hline Health & & & & & & 4 & 1 \\
\hline
\end{tabular}




\section{Women's Health Problems}

\begin{tabular}{|c|c|c|c|c|c|c|c|c|c|}
\hline & Bleeding & Goiter & Bone pain & Asthma & Prolapes & $\begin{array}{l}\text { B. } \\
\text { Pressure }\end{array}$ & $\begin{array}{l}\text { Dysure } \\
\mathrm{a}\end{array}$ & No & Rank \\
\hline Bleeding & & bleeding & bone pain & bleeding & prolapes & b. pressure & dysurea & 2 & 3 \\
\hline Goiter & & & goiter & asthma & goiter & b. pressure & dysurea & 2 & 3 \\
\hline Bone pain & & & & bone pain & bone pain & bone pain & dysurea & 4 & 1 \\
\hline Asthma & & & & & asthma & b. pressure & asthma & 3 & 2 \\
\hline Prolapse & & & & & & b. pressure & $\begin{array}{l}\text { prolape } \\
\mathrm{s}\end{array}$ & 2 & 3 \\
\hline B. Pressure & & & & & & & dysurea & 4 & 1 \\
\hline Dysurea & & & & & & & & 4 & 1 \\
\hline
\end{tabular}

\begin{tabular}{|l|l|l|l|l|l|l|}
\hline & Back pain & Chest pain & Goiter & Bleeding & Number & Rank \\
\hline Back pain & & chest pain & Goiter & Bleeding & 0 & 4 \\
\hline Chest pain & & & chest pain & Bleeding & 2 & 2 \\
\hline Goiter & & & Bleeding & 1 & 3 \\
\hline Bleeding & & & & 3 & 1 \\
\hline
\end{tabular}

\begin{tabular}{|l|l|l|l|l|l|l|l|}
\hline & Bleeding & Back pain & Headache & Prolapse & $\begin{array}{l}\text { Stomach- } \\
\text { Ache }\end{array}$ & Asthma & Rank \\
\hline Bleeding & & Waist pain & Bleeding & Prolapse & $\begin{array}{l}\text { Stomach- } \\
\text { Ache }\end{array}$ & Asthma & 2 \\
\hline Back pain & & Back pain & Back pain & $\begin{array}{l}\text { Stomach- } \\
\text { Ache }\end{array}$ & Asthma & 1 \\
\hline Headache & & & Headache & Headache & Headache & 1 \\
\hline Prolapse & & & Stomach-ache & Asthma & 3 \\
\hline $\begin{array}{l}\text { Stomach- } \\
\text { Ache }\end{array}$ & & & & Stomach- \\
Asthma
\end{tabular}


Annex $3 \quad$ Examples of lifelines

Lifeline of a 40-year-old widow in Yakawlang

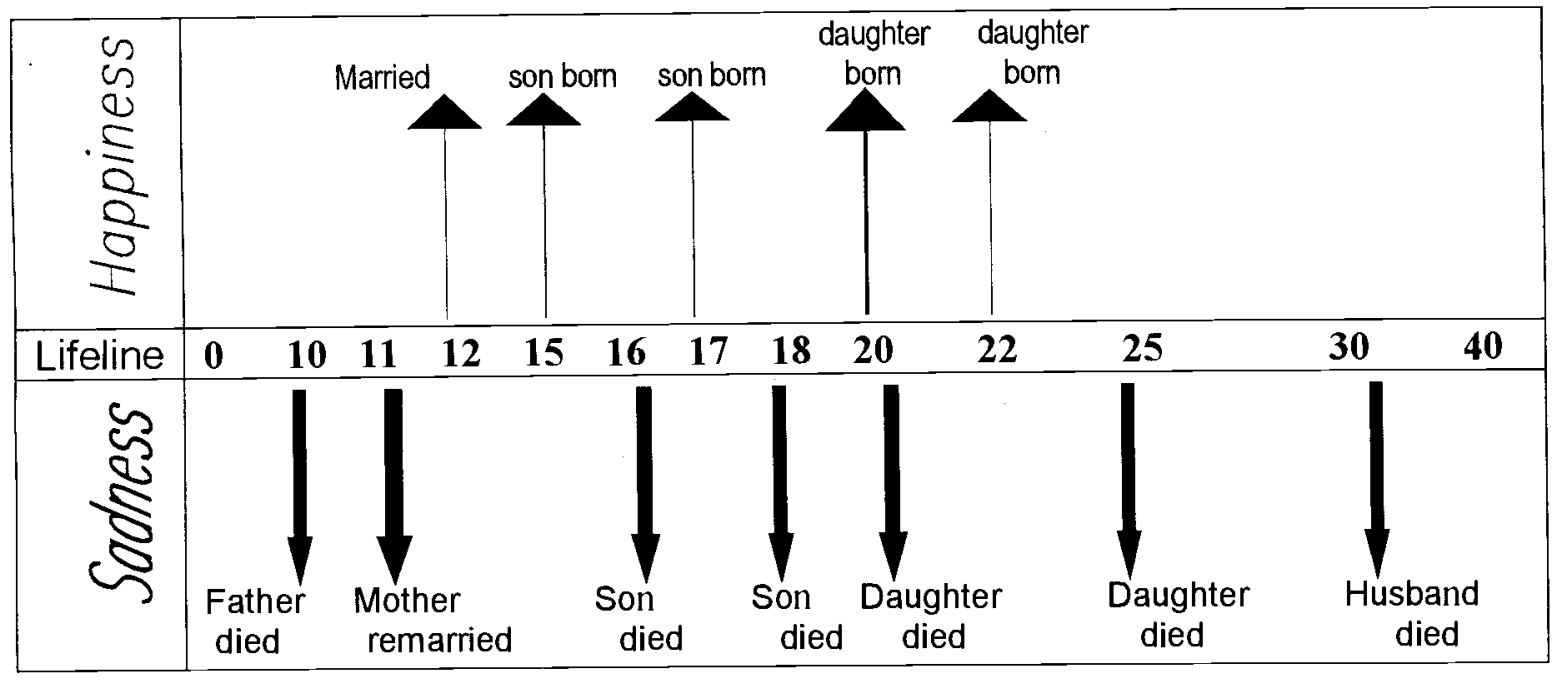

Lifeline of 25-year-old female, Yakawlang

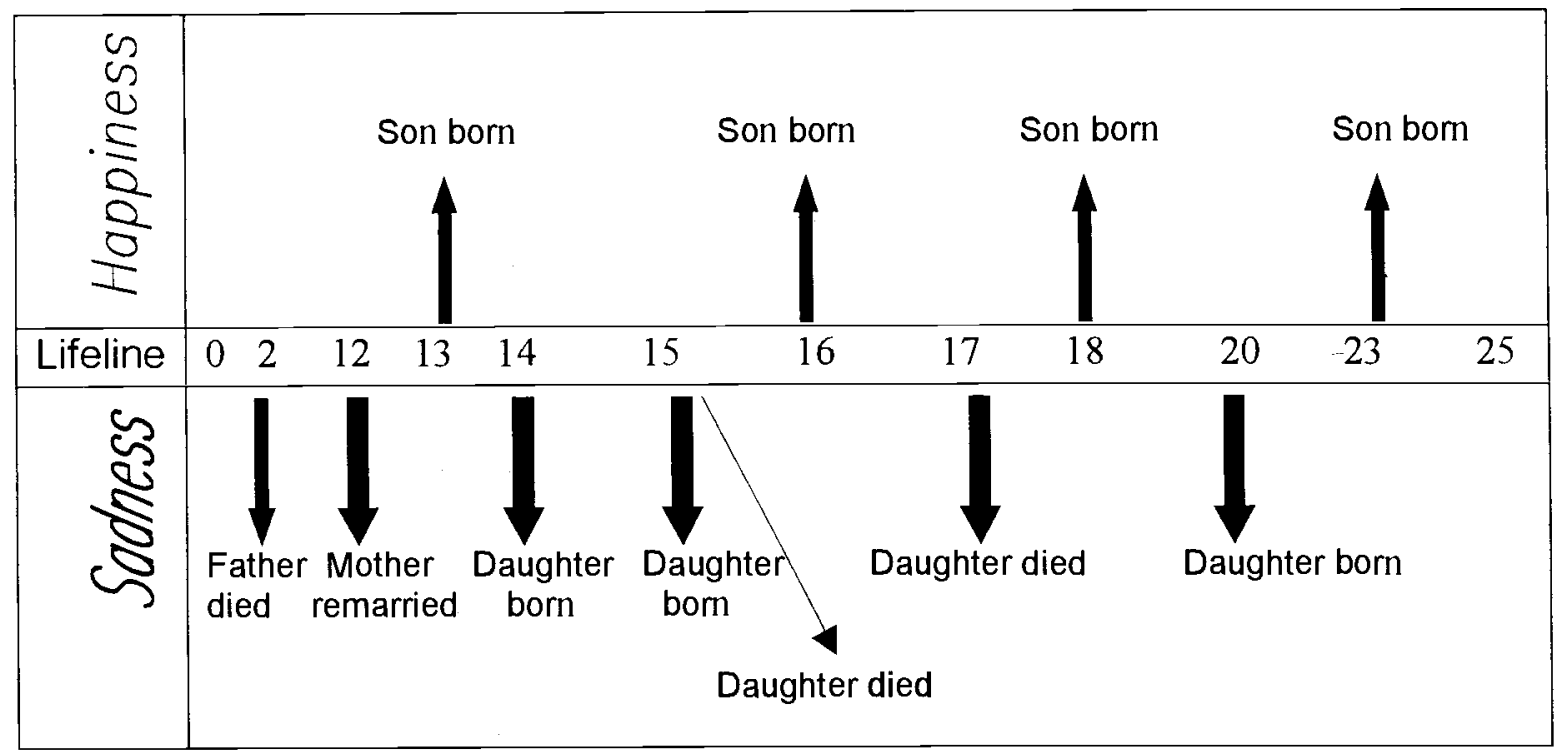

71 